\title{
RNP-MaP: In-cell analysis of protein interaction networks defines functional hubs in RNA
}

Chase A. Weidmann ${ }^{1,2}$, Anthony M. Mustoe ${ }^{1}$, Parth B. Jariwala ${ }^{1}$, J. Mauro Calabrese ${ }^{2,3}$, Kevin M. Weeks ${ }^{1, *}$

${ }^{1}$ Department of Chemistry, University of North Carolina, Chapel Hill NC 27599-3290

${ }^{2}$ Lineberger Comprehensive Cancer Center, University of North Carolina, Chapel Hill, NC 27599

${ }^{3}$ Department of Pharmacology, University of North Carolina, Chapel Hill, NC 27599, USA

*correspondence, weeks@unc.edu

\section{ABSTRACT}

RNAs interact with networks of proteins to form complexes (RNPs) that govern many biological processes, but these networks are currently impossible to examine in a comprehensive way. We developed a live-cell chemical probing strategy for mapping protein interaction networks in any RNA with single-nucleotide resolution. This RNP-MaP strategy (RNP network analysis by mutational profiling) simultaneously detects binding by and cooperative interactions involving multiple proteins with single RNA molecules. RNP-MaP revealed that two structurally related, but sequence-divergent noncoding RNAs, RNase P and RMRP, share nearly identical RNP networks and, further, that protein interaction network hubs identify function-critical sites in these RNAs. RNP-MaP identified numerous protein interaction networks within the XIST long noncoding RNA that are conserved between mouse and human RNAs and distinguished communities of proteins that network together on XIST. RNP-MaP data show that the Xist E region is densely networked by protein interactions and that PTBP1, MATR3, and TIA1 proteins each interface with the XIST E region via two distinct interaction modes; and we find that the XIST E region is sufficient to mediate RNA foci formation in cells. RNP-MaP will enable discovery and mechanistic analysis of protein interaction networks across any RNA in cells. 


\section{INTRODUCTION}

RNA-protein complexes (RNPs) govern both mRNA regulation and noncoding RNA (ncRNA) function $^{1,2}$. Understanding how RNPs assemble and function, involving both one RNA-one protein interactions and multi-component interaction networks, is thus critical for characterizing many biological processes and mechanisms. To date, biochemical approaches have defined in detail protein interactions required for a number of RNP assemblies ${ }^{3}$, and high-resolution structural approaches ${ }^{4-6}$ have revolutionized our understanding of small and large RNP architectures. Nonetheless, it remains challenging to characterize RNP assemblies and their interacting networks within living systems.

Current methods for characterizing RNPs in live cells suffer from several limitations. Crosslinking and immunoprecipitation (CLIP) approaches have enabled identification of binding sites for individual RNA-binding proteins transcriptome-wide ${ }^{7}$. However, CLIP suffers from strong experimental biases ${ }^{8}$, is limited in binding-site resolution, assesses only a single protein at a time, and requires a unique antibody or exogenous tag. Methods that focus on cataloging RNA-binding proteins, like mass spectrometry, cannot simultaneously locate protein-binding sites on RNA nor easily prioritize proteins in terms of function ${ }^{9}$. These limitations obscure the importance of binding by multiple proteins to individual RNAs. Major unaddressed challenges are: (1) How do multiple RNA-binding proteins cooperate on an RNA to form networks, and (2) Which protein interaction networks are the most critical for function of an individual RNA?

Here we describe an experimentally concise strategy that locates sites of protein interaction on any targeted RNA in live cells with nucleotide resolution, reports on multi-protein interaction networks present on single RNA molecules, and identifies network hubs most integral to the function of an RNP. We validated this approach, termed ribonucleoprotein network analysis by mutational profiling or RNP-MaP, on small and large RNPs with known architectures. RNP-MaP was then used to define critical functional regions of the XIST long noncoding RNA (IncRNA), to categorize XIST-binding proteins into distinct interactive groups, and to identify features of the functionally important XIST E region. RNP-MaP will be widely useful for characterizing RNP biology, particularly in defining functionally critical and disease-relevant domains in large messenger and non-coding RNAs. 


\section{RESULTS}

\section{RNP-MaP Validation}

To comprehensively map protein interaction networks of an RNA of interest, we identified a cellpermeable reagent, NHS-diazirine (SDA), that can rapidly label RNA nucleotides at sites of protein binding. SDA has two reactive moieties: a succinimidyl ester and a diazirine (Fig. 1a). Succinimidyl esters react to form amide bonds with amines such as those found in lysine side chains. When photoactivated with long-wavelength ultraviolet light (UV-A, $365 \mathrm{~nm}$ ), diazirines form carbene or diazo intermediates ${ }^{10}$, which are broadly reactive to nucleotide sugar and base moieties. The two-step reaction of SDA thus crosslinks protein lysine residues with RNA with a distance governed by SDA linker length ( $4 \AA$ ) and lysine flexibility $(6 \AA)$. Lysine is one of the most prevalent amino acids in RNA-binding domains ${ }^{11}$, and photo-intermediate lifetimes are short; thus, SDA is expected to crosslink short-range RNA-protein interactions relatively independently of local RNA structure or protein properties. To perform crosslinking, live cells are treated with SDA for a short time and then exposed to UV-A light.

To detect SDA-mediated RNA-protein crosslinks, we use the MaP reverse transcription technology (Fig. 1b). SDA-treated cells are lysed and crosslinked proteins are digested to short peptide adducts. Adduct-containing RNA is then used as a template for relaxed-fidelity reverse transcription $^{12,13}$. Under MaP conditions, reverse transcriptase reads through adduct-containing nucleotides and incorporates non-templated nucleotides into the product DNA at the site of RNAprotein crosslinks. Importantly, because transcription reads through adducts, RNP-MaP detects multiple protein crosslinks that co-occur on single RNA molecules (Fig. 1b). Sequencing the DNA product and locating sites of mutation thus reveals two key features of an RNA-protein complex: RNP-MaP adducts at individual nucleotides report locations of protein binding, and correlated crosslinking across multiple nucleotides reveals higher-order protein interaction networks.

In experiments with U1 small nuclear RNA (snRNA), ribonuclease P RNA (RNase P), and the RNA component of mitochondrial RNA processing endoribonuclease (Rmrp) in mouse embryonic stem cells, the RNP-MaP signal was strictly dependent on treatment of cells with both UV and SDA (Fig. 1c and Fig. S1). To confirm that RNP-MaP adducts reflect bound proteins, we performed RNP-MaP on RNA extracted from cells (removing protein), which yielded substantially reduced adduct formation rates (Fig. 1C and Fig. S1). Use of either a diazirine ethanol compound (DA-EtOH), which has no lysine-reactive group, or SDA with a pre-quenched NHS-ester 
eliminated adduct formation, indicating that diazirine reactivity with RNA requires conjugation with lysine residues (Fig. 1d). In sum, RNP-MaP measures crosslinking events that are strictly dependent on SDA and UV dosage and that only occur in the presence of both RNA and cellular proteins.

We quantified distances between lysine residues and SDA-reactive sites of human U1, RNase P, and $18 \mathrm{~S}$ and $28 \mathrm{~S}$ ribosomal RNAs by comparison to high-resolution structures ${ }^{4,6,14}$. From these experiments, we derived nucleotide-specific normalization factors for calculating reactivity thresholds relative to experimental medians (Fig. S2). These normalization factors can be applied to RNP-MaP experiments on RNAs whose structure and protein partners are unknown, enabling de novo identification of protein-bound nucleotides with high confidence (Fig. S2). Nucleotides whose SDA-enhanced mutation rates (reactivities) exceed computed reactivity thresholds are called "RNP-MaP sites". Reactivities were highly reproducible, nucleotides with higher reactivities were shorter distances from lysine amines, RNP-MaP sites were observed in both paired and unpaired regions of RNA and independently of nucleotide identity, and nucleotides distant from bound proteins rarely passed reactivity thresholds (Fig. S3). RNP-MaP sites identified in Rmrp and RNase P RNAs agreed with orthogonal $\triangle$ SHAPE chemical probing ${ }^{15,16}$ and photo-lysine metabolic labeling ${ }^{17}$ (Fig. S4). These experiments demonstrated that RNP-MaP identifies shortdistance crosslinks between an RNA and bound proteins.

\section{RNP-MaP defines protein interaction networks in the U1 snRNP}

When RNP-MaP was used to examine protein interaction networks in the U1 snRNP in human HEK293 cells, we observed that RNP-MaP sites clustered in regions of U1 RNA known to bind proteins $^{14,18}$ (Fig. 2a, 2b). Notably, RNP-MaP sites occurred at all four ribonucleotides and in both single-stranded and base-paired regions (Fig. 2c), consistent with non-selective diazirine reactivity. The majority of RNP-MaP sites were within $9 \AA$ of a lysine residue (Fig. 2b). We identified additional RNP-MaP sites in U1 stem loop 2 that, although close to the U1A binding site, do not correspond to known interaction sites (Fig. 2c). Only one of two RNA recognition motifs (RRMs) within the U1A protein is visualized in high-resolution structures ${ }^{14}$, and the RNPMaP sites that extend outside of the known recognition site may reflect binding by the other U1A RRM or an unidentified protein component of the U1 snRNP.

Our RNP-MaP data also revealed multiple sites that were crosslinked in a correlated manner, reflecting RNA-mediated through-space protein-protein communication, in networks consistent 
with the known architecture of the U1 snRNP complex (Fig. 2b, 2c). Pairs of RNA sites exhibiting statistically significant co-mutations, termed RNP-MaP correlations, were identified using an established G-test framework ${ }^{19}$ (Fig. S2 and Fig. S5). The highest density and strength of correlations involved nucleotides bound by the Sm protein complex (Fig. 2b and Fig. S5), whose initial loading onto $U 1$ is necessary for the maturation of the snRNP ${ }^{20}$. The second-highest density and strength of correlations were observed at the binding site for SNUPN protein, which recognizes Sm-bound U1 RNA and imports the RNP into the nucleus where it ultimately functions $^{21}$. RNP-MaP correlations also reflect the long-distance network interactions between $70 \mathrm{~K}$ and the Sm complex important for U1 snRNP assembly ${ }^{22}$. Only a few weak correlations were observed between the Sm core and U1A, consistent with the observation that U1A binds independently and that the stem-loop to which it binds is expendable for splicing activity ${ }^{23}$. Together, our data show that RNP-MaP correctly reveals protein interaction networks, pinpoints the central hubs of these networks, and identifies interactions important for assembly and function in the U1 snRNP.

\section{RNP-MaP reveals conserved protein interaction networks in RNase $P$ and RMRP RNAs}

RNase $P$ and RMRP are structurally related, but sequence divergent, non-coding RNAs that bind overlapping sets of proteins to form RNP endonucleases that cleave distinct substrates $6,19,24$. RNP-MaP revealed that, despite differing sequences and substrates, the two RNPs have nearly identical protein interaction networks. We compared RNP-MaP sites to known protein interactions within RNase $\mathrm{P}^{6}$ and identified binding regions for 9 of the 10 RNase $\mathrm{P}$ interaction partners (Fig. 3a). Only Rpp14 binding was not detected, an absence explained by its limited interface with the RNA (of only eight amino acids, one of which is lysine). Comprehensive atomic resolution structural data does not exist for RMRP; however, the matching patterns of RNP-MaP sites for RNase $P$ and RMRP suggest that most protein interaction sites outside of their specificity domains are shared. Relative locations of RNP-MaP sites are also conserved between human and mouse homologs of RNase P and RMRP (Fig. S6).

Strikingly, the patterns of through-space RNP-MaP correlations for the RNase P and RMRP RNAs are nearly identical after alignment by structural domains (Fig. 3b). For RNase $P$, the strongest correlations define three hubs involving the specificity domain, the substrate cleavage site, and the Rpp20/25 dimer (which links the specificity domain and cleavage site), and these hubs are conserved in RMRP (Fig. 3c). Omission of protein complexes that comprise each hub suppresses or eliminates RNase $\mathrm{P}$ catalytic function in vitro ${ }^{25}$. Our RNase P and RMRP data thus 
identify shared protein interactions and interaction network hubs in two structurally related but sequence divergent RNAs, confirm conservation of these interaction networks between mice and humans, and highlight the ability of RNP-MaP to identify functional regions in large noncoding RNAs.

\section{RNP-MaP identifies conserved protein interaction networks in the XIST IncRNA}

The 20-kb X-inactive specific transcript (denoted Xist in mouse, XIST in human) is a IncRNA that controls X-chromosome dosage compensation in eutherian mammals ${ }^{26}$. The Xist/XIST sequence is only minimally conserved between mice and humans, despite accomplishing the same functions. We used RNP-MaP to examine whether Xist/XIST protein interaction networks are conserved in the absence of sequence conservation. After in-cell crosslinking, Xist/XIST RNAs were enriched by RNA antisense pull-down ${ }^{27}$, and RNA-protein interactions were read out by randomly primed MaP RT (Fig. S7). Data were obtained for $97 \%$ of nucleotides in both RNAs, including over four nucleobases and in both structured and unstructured regions (Fig. S8).

Strikingly, regions with high RNP-MaP site density in Xist/XIST corresponded to the A, B, C, D, and $E$ regions (Fig. 4a), which are each known to contain distinct repetitive sequences important for Xist localization, assembly, and chromatin silencing ${ }^{28-35}$. High RNP-MaP density was observed at each of these repetitive regions despite changes in copy number (human XIST contains two copies of the $B$ region) and changes in size, relative position, and sequence (C, D, and $\mathrm{E}$ regions differ extensively between mice and humans $)^{36}$. We also observed multiple additional regions of Xist/XIST, not previously defined in terms of Xist function, with strong RNPMaP signal density that are clearly conserved between mice and humans.

We compared the RNP-MaP signal to eCLIP site density, measured in experiments in K562 cells $^{37}$, from 30 proteins whose binding sites on XIST have been mapped and were reproducible between eCLIP replicates. We observed good agreement between RNP-MaP and eCLIP data, especially over the human XIST A and E regions (Fig. 4b). The eCLIP sites of human HNRNPK protein, whose mouse homologue mediates recruitment of Polycomb through the $B$ and $C$ regions of mouse Xist ${ }^{29,38}$, closely mirror RNP-MaP site density across the human XIST D region and overlap human XIST B and C regions (Fig. S8), supporting a model wherein the $B, C$, and D regions of Xist/XIST are functionally analogous ${ }^{39}$. eCLIP site density tends to be lower than RNPMaP density in multiple regions, for example between the two human XIST B regions, likely reflecting that only a subset of Xist-binding proteins have been mapped by eCLIP. Together, 
these data show that RNP-MaP efficiently identifies protein-binding sites critical for function in very long IncRNAs.

RNP-MaP correlation patterns in the Xist/XIST RNAs showed that protein-bound regions form higher-order interaction networks with distinct levels of interactivity, features invisible to alternative analysis strategies. Six highly networked regions were detected in human XIST RNA, and at least five of these regions are conserved in mouse Xist RNA (Fig. 4a). Low sequencing depth precluded identification of high-confidence correlations in the human XIST A region. The $E$ region of Xist/XIST represents an extreme example in which an extended region (spanning 1-1.5 $\mathrm{kb}$ ) forms a highly cooperative protein interaction network as evidenced by high correlation strength densities. There exist other highly protein-bound regions, such as the $\mathrm{C}$ region of mouse Xist and portions of Xist/XIST D region, that are highly bound but do not show correspondingly strong correlations (Fig. 4a); in these regions proteins that bind do so more independently of one another. Thus, RNP-MaP data identify distinct local patterns of RNA-protein interaction networks, detected as low and high levels of network interactivity.

\section{Communities of XIST-binding proteins}

We next used RNP-MaP correlations to directly analyze inter-protein communication in the XIST RNP. We performed a network analysis of high-confidence eCLIP sites that are linked by RNPMaP correlations to reveal communities of XIST-interacting proteins. We identified four communities of XIST-binding proteins by maximizing modularity of the network ${ }^{40,41}$ while weighting by correlation strength (mutual information), (Fig. 5, Table S1). We categorized these communities based on the functions of XIST sequences to which the proteins bind, including $5^{\prime}$ Silencing, Compartmentalization, Splicing, and U/C communities (Fig. 5 and Fig. S8). The communities are distinct: correlations between proteins from different communities occur significantly fewer times than expected based on the proximity of their binding sites (Table S2).

Proteins in the $5^{\prime}$ Silencing community bind primarily to the $5^{\prime}$ region of XIST, which includes the silencing-critical A region ${ }^{28}$. Community members include factors involved in XIST processing, XIST stability, and XIST-mediated silencing - UCHL5 ${ }^{42}$, EXOSC5 ${ }^{43}, \mathrm{HNRNPUL}^{44}$, and RBM15 ${ }^{45}$, (Fig. 5). Silencing community members TARDBP and RBM22 are RNA-dependent regulators of transcription ${ }^{46}$ but have not yet been directly implicated in $\mathrm{X}$ chromosome silencing. The significant interactivity of the binding sites of the 5 ' Silencing community members suggests formation of a specific coordinated RNP on XIST. 
The strongest inter-protein correlations are observed between Compartmentalization community members PTBP1, MATR3, and TIA1, which bind in the XIST E region (Fig. 5 and Fig. S8). XIST $E$ region is critical to maintenance of the silenced $X$ chromosome compartment $^{33}$. Notably, PTBP1, MATR3, and TIA1 each undergo liquid-liquid phase-transitions to form RNA granules ${ }^{47-}$ 50, a feature consistent with the formation of an XIST-mediated compartment. PTBP1 and MATR3 interact together on other RNAs as well, creating multi-valent interactions typical of RNA-protein granules ${ }^{51,52}$.

The Splicing community includes components known to control splicing (U2AF2, SRSF1, TRA2A, $A Q R$, and ILF3) $)^{53-55}$ and a chromatin modulator (GRWD1) ${ }^{56}$. All Splicing community proteins, except for TRA2A, bind to XIST at exon-exon junctions (Fig. S8), consistent with a function in splicing of XIST transcripts.

The smallest community (U/C) includes two HNRNPs ( $U$ and $C$ ) already known to interact with one another ${ }^{57}$. HNRNPs $U$ and $C$ do not strongly interact with other communities and interact sparsely across XIST, suggesting that the roles these proteins play in $\mathrm{X}$ chromosome silencing do not require significant interaction with other networks. Together, this analysis reveals how RNPMaP can define RNP communities with distinct levels of networking (low versus high), associated with IncRNA functions.

PTBP1, MATR3, and TIA1 recognize XIST E region via two binding modes

The XIST E region is critical for maintaining the silenced $X$ chromosome compartment ${ }^{32,33}$, is distinguished by strong inter-protein network connectivity (Fig. 4a), and includes binding sites for the proteins most strongly linked by RNP-MaP correlations: PTBP1, MATR3, and TIA1 (Fig. 5 and Fig. S8). To assess how each protein interfaces with the XIST E region, we used RNP-MaP to examine binding by purified recombinant PTBP1, MATR3, and TIA1 to in vitro transcribed RNA spanning the human XIST E region.

PTBP1, MATR3, and TIA1 each bound the XIST E region RNA with similar patterns (Fig. 6a). Both the quantity and reactivity of RNP-MaP sites increased in a protein concentration-dependent way (Fig. S9). Comparing in-cell RNP-MaP sites in the XIST E region to in vitro RNP-MaP sites for PTBP1, MATR3, and TIA1 revealed two patterns: (i) regions with similar in vitro and in-cell RNP-MaP signals and (ii) regions with high in-cell RNP-MaP signals not observed in vitro (Fig. 
6a). In addition, a notable number of RNP-MaP sites for PTBP1, MATR3, and TIA1 observed in vitro were not identified by eCLIP. Thus, the full list of proteins that bind to the XIST E extends beyond those currently mapped by eCLIP, and the CLIP data do not include all XIST E sequences capable of being bound by PTBP1, MATR3, and TIA1.

Two distinct classes of 9-mer motifs were bound by each protein (Fig. 6b). The pyrimidine-rich motifs of class 1 are similar to motifs previously defined for each protein in vitro ${ }^{58}$ and by CLIP methods ${ }^{59-61}$, whereas the motif class 2 is uniquely identified by RNP-MaP. E-values for motifs of class 1 were not significant because of the high frequency of uridine nucleotides in the $E$ region $(36 \%)$ and the low complexity of the motifs. In contrast, the purine-rich class 2 motif was significantly enriched in RNP-MaP sites from each protein in vitro (Fig. 6b). Class 1 and 2 motifs were also found by analysis of RNP-MaP sites identified in cells, with enrichment scores comparable to those observed in vitro (Fig. 6b). Under our simplified in vitro binding conditions, PTBP1, MATR3, and TIA1 confer higher RNP-MaP reactivity on class 2 motifs than the class 1 motifs (Fig. S9 and S10). In cells, RNP-MaP densities and reactivities at class 1 and 2 motifs are more similar (Fig. S10). Thus, our data suggest that PTBP1, MATR3, and TIA1 recognize overlapping regions of the XIST E region through two distinct modes of recognition that are likely influenced by the presence of other XIST-binding proteins.

Interestingly, while RNP-MaP readily detects binding at both motif classes, class 2 motifs were not detected by eCLIP for PTBP1, MATR3, or TIA1 (Fig. 6a). This discrepancy likely reflects that eCLIP signal relies largely on uridine nucleotides to achieve crosslinking ${ }^{8}$ and the density of uridine nucleotides is low in the XIST E region where class 2 motifs are present (Fig. S10). Overall, RNP-MaP identifies a more comprehensive set of protein-binding sites such that $97 \%$ of eCLIP sites in XIST (of the 151 analyzed) overlap RNP-MaP sites, but only 35\% of RNP-MaP sites (of 3766) exist within an eCLIP site. RNP-MaP does not rely on specific nucleotides for reactivity or enrichment by antibody binding and thus can identify more diverse protein recognition motifs, but RNP-MaP does not independently assign an interaction site to a specific protein.

\section{Protein-interactive $E$ region promotes RNA focus formation in cells}

PTBP1, MATR3 and TIA1 proteins are implicated in formation of RNA foci ${ }^{4-50}$, likely through multivalent interactions between RNAs and proteins ${ }^{62}$, consistent with the highly interactive protein networks we measure in the XIST E region (Fig. 4a). To examine whether protein 
interactions with the $E$ region can promote foci formation, we inserted the $E$ region into an RNA reporter and compared its expression and localization to reporters containing other highly proteininteractive XIST regions or a non-XIST sequence. Reporter RNA containing the XIST E region was expressed at significantly lower levels than RNA reporters containing other highly interactive XIST sequences (Fig. 6c). Furthermore, the $\mathrm{E}$ region-containing reporter, but not reporters containing other regions of XIST, formed large foci in cells (Fig. 6d). These foci, formed in the cytoplasm by reporter RNAs containing the $\mathrm{E}$ region, are reminiscent of nuclear XIST particles that form on chromatin during $X$ chromosome inactivation ${ }^{28}$. Thus, the highly interconnected RNP network that assembles on the XIST E region, likely in concert with binding by granule-associated proteins PTBP1, MATR3, and TIA1, can organize an RNA into XIST-like foci. Our data support the role of the $E$ region in organization of the XISTcompartment ${ }^{32,33}$ and highlight the ability of RNP-MaP to discover and characterize novel functional motifs in noncoding RNAs.

\section{DISCUSSION}

Here we demonstrate that RNP-MaP enables rapid and experimentally concise characterization of functionally important protein-RNA interaction networks: Protein binding sites are identified across an RNA with low sequence and structure biases, mutually exclusive interaction networks are distinguishable by their correlation patterns, highly interactive hubs are identified, and functionally important regions are assessed by their binding site density and interconnectivity.

RNP-MaP revealed new insights into the assembly of small RNPs U1, RNase P, and RMRP. Each RNP has three or four interaction network hubs. Intriguingly, the strongest protein network hubs in each RNA correspond to regions known to be central to RNP assembly and activity: the Sm complex assembly site in U1 and the substrate cleavage sites in RNase P and RMRP. The next strongest hubs are regions that comprise additional critical components in each RNP: the SNUPN protein binding site, which traffics the Sm-bound U1 RNA into the nucleus, and the specificity domains of RNase $P$ and RMRP, which recruit substrates to the active sites. The unique ability of RNP-MaP to rank interaction networks by correlation strength will aid in discovery and prioritization of functional elements in noncoding RNAs.

Prior structure probing analyses of the mouse Xist RNA revealed that repeat-containing regions are structurally dynamic and accessible for protein binding, and these regions were proposed to function as "landing pads" for proteins ${ }^{16}$. Our RNP-MaP study now reveals that repeat-containing 
sequences in Xist/XIST are extensively bound by proteins and that these interactions are often highly networked. Granule-associated proteins PTBP1, MATR3, and TIA1 bind throughout the XIST E region, and the $\mathrm{E}$ region promoted foci formation by a heterologous reporter RNA in cells. These data suggest that protein interaction networks in the $E$ region contribute to formation of a phase-separated particle, thus playing a role in XIST compartmentalization in vivo. Similar roles for Xist repeats, including in the $E$ region, have recently been proposed based on analysis of Xist particle shape and composition ${ }^{63}$. Importantly, RNP-MaP directly identified hubs of conserved function in the absence of additional information and for RNAs lacking extensive sequence conservation. Our study additionally mapped many new highly-networked hubs that merit detailed further study.

There are estimated to be at least as many noncoding RNA genes as there are protein-coding genes $^{64}$. It remains challenging to discern the overall functions of noncoding RNA transcripts and to identify function-critical regions of a long noncoding RNA. Conserved macromolecular structure implies function and, in the case of eukaryotic noncoding RNPs, structure and function are reliant on RNA-protein interaction networks ${ }^{65}$. The ability of RNP-MaP to identify function-critical regions of RNA and their interconnected protein networks de novo is likely to have a significant impact on understanding of the thousands of noncoding RNAs whose functions and protein networks are unexplored. RNP-MaP can be further applied to reveal how interaction networks form and dissociate during complex assembly in both coding and non-coding RNAs, how networks differ between cell types, and how networks change in response to stimuli.

\section{ACKNOWLEDGEMENTS}

The work was supported by grants from the US National Science Foundation (MCB-1121024) and National Institutes of Health (R35 GM122532) to K.M.W. C.A.W. is a postdoctoral fellow of the American Cancer Society (ACS 130845-RSG-17-114-01-RMC). J.M.C. was supported by NIH grant R01 GM121806. Xist and XIST antisense probes were provided by the Guttman laboratory (CalTech), and we thank Mario Blanco for his initial support in their application. XIST eCLIP data from published work were provided upon request by the Yeo laboratory (UCSD), and we thank Gene Yeo (UCSD), Meredith Corley (UCSD), and Daniel Sprague (UNC) for support in formatting these data for integration into this work and for helpful comments on the project. 


\section{AUTHOR CONTRIBUTIONS}

C.A.W. and P.B.J. conducted experiments, and C.A.W., A.M.M. and K.M.W. analyzed data. C.A.W., J.M.C., and K.M.W. designed and interpreted experiments. The manuscript was written by C.A.W. and K.M.W. with input from all authors.

\section{COMPETING INTERESTS}

A.M.M. is an advisor to and K.M.W. is an advisor to and holds equity in Ribometrix, to which mutational profiling technologies have been licensed.

\section{DATA AVAILABILITY}

Raw and processed sequencing datasets analyzed in this report will be made available upon reasonable request and deposited in the Gene Expression Omnibus database (in process).

\section{CODE AVAILABILITY}

ShapeMapper2, deltaSHAPE, SuperFold, and RingMapper software used for analysis are available here (http://weeks.chem.unc.edu/software.html) and here (https://github.com/WeeksUNC). MEME, VARNA, PyMol, and Gephi are freely open source software. 


\section{REFERENCES}

1. Singh, G., Pratt, G., Yeo, G. W. \& Moore, M. J. The Clothes Make the mRNA: Past and Present Trends in mRNP Fashion. Annu. Rev. Biochem. 84, 325-354 (2015).

2. Guttman, M. \& Rinn, J. L. Modular regulatory principles of large non-coding RNAs. Nature 482, 339-346 (2012).

3. Gehring, N. H., Wahle, E. \& Fischer, U. Deciphering the mRNP Code: RNA-Bound Determinants of Post-Transcriptional Gene Regulation. Trends in Biochemical Sciences 42, 369-382 (2017).

4. Anger, A. M. et al. Structures of the human and Drosophila 80 S ribosome. Nature 497, 8085 (2013).

5. Plaschka, C., Lin, P. C., Charenton, C. \& Nagai, K. Prespliceosome structure provides insights into spliceosome assembly and regulation. Nature 559, 419-422 (2018).

6. Wu, J. et al. Cryo-EM Structure of the Human Ribonuclease P Holoenzyme. Cell 175, 1393-1404.e11 (2018).

7. Ule, J., Hwang, H. W. \& Darnell, R. B. The future of cross-linking and immunoprecipitation (CLIP). Cold Spring Harb. Perspect. Biol. 10, (2018).

8. Wheeler, E. C., Van Nostrand, E. L. \& Yeo, G. W. Advances and challenges in the detection of transcriptome-wide protein-RNA interactions. Wiley Interdiscip. Rev. RNA 9, (2018).

9. Ramanathan, M., Porter, D. F. \& Khavari, P. A. Methods to study RNA-protein interactions. Nature Methods 16, 225-234 (2019).

10. Das, J. Aliphatic diazirines as photoaffinity probes for proteins: Recent developments. Chemical Reviews 111, 4405-4417 (2011).

11. Krüger, D. M., Neubacher, S. \& Grossmann, T. N. Protein-RNA interactions: Structural characteristics and hotspot amino acids. RNA 24, 1457-1465 (2018).

12. Siegfried, N. A., Busan, S., Rice, G. M., Nelson, J. A. E. \& Weeks, K. M. RNA motif discovery by SHAPE and mutational profiling (SHAPE-MaP). Nat. Methods 11, 959-965 (2014).

13. Smola, M. J., Rice, G. M., Busan, S., Siegfried, N. A. \& Weeks, K. M. Selective 2'-hydroxyl acylation analyzed by primer extension and mutational profiling (SHAPE-MaP) for direct, versatile and accurate RNA structure analysis. Nat. Protoc. 10, 1643-1669 (2015).

14. Kondo, Y., Oubridge, C., van Roon, A. M. M. \& Nagai, K. Crystal structure of human U1 snRNP, a small nuclear ribonucleoprotein particle, reveals the mechanism of 5 ' splice site 
recognition. Elife 4, 1-19 (2015).

15. Smola, M. J., Calabrese, J. M. \& Weeks, K. M. Detection of RNA-Protein Interactions in Living Cells with SHAPE. Biochemistry 54, 6867-6875 (2015).

16. Smola, M. J. et al. SHAPE reveals transcript-wide interactions, complex structural domains, and protein interactions across the Xist IncRNA in living cells. Proc. Natl. Acad. Sci. U. S. A. 113, 10322-10327 (2016).

17. Yang, T., Li, X. M., Bao, X., Fung, Y. M. E. \& Li, X. D. Photo-lysine captures proteins that bind lysine post-translational modifications. Nat. Chem. Biol. 12, 70-72 (2016).

18. Kühn-Hölsken, E. et al. Mapping the binding site of snurportin 1 on native u1 snRNP by cross-linking and mass spectrometry. Nucleic Acids Res. 38, 5581-5593 (2010).

19. Mustoe, A. M., Lama, N. N., Irving, P. S., Olson, S. W. \& Weeks, K. M. RNA base-pairing complexity in living cells visualized by correlated chemical probing. Proc. Natl. Acad. Sci. 116, 24574-24582 (2019).

20. Matera, A. G. \& Wang, Z. A day in the life of the spliceosome. Nature Reviews Molecular Cell Biology 15, 108-121 (2014).

21. Huber, J., Dickmanns, A. \& Lührmann, R. The importin- $\beta$ binding domain of snurportin1 is responsible for the Ran- and energy-independent nuclear import of spliceosomal $U$ snRNPs in vitro. J. Cell Biol. 156, 467-479 (2002).

22. So, B. R. et al. A U1 snRNP-specific assembly pathway reveals the SMN complex as a versatile hub for RNP exchange. Nat. Struct. Mol. Biol. 23, 225-230 (2016).

23. Will, C. In vitro reconstitution of mammalian U1 snRNPs active in splicing: the U1-C protein enhances the formation of early (E) spliceosomal complexes. Nucleic Acids Res. 24, 4614-4623 (1996).

24. Esakova, O. \& Krasilnikov, A. S. Of proteins and RNA: The RNase P/MRP family. RNA 16, 1725-1747 (2010).

25. Perederina, A., Berezin, I. \& Krasilnikov, A. S. In vitro reconstitution and analysis of eukaryotic RNase P RNPs. Nucleic Acids Res. 46, 6857-6868 (2018).

26. Sahakyan, A., Yang, Y. \& Plath, K. The Role of Xist in X-Chromosome Dosage Compensation. Trends in Cell Biology 28, 999-1013 (2018).

27. Engreitz, J. M. et al. The Xist IncRNA exploits three-dimensional genome architecture to spread across the $X$ chromosome. Science (80-. ). 341, (2013).

28. Wutz, A., Rasmussen, T. P. \& Jaenisch, R. Chromosomal silencing and localization are mediated by different domains of Xist RNA. Nat. Genet. 30, 167-174 (2002).

29. Colognori, D., Sunwoo, H., Kriz, A. J., Wang, C. Y. \& Lee, J. T. Xist Deletional Analysis 
Reveals an Interdependency between Xist RNA and Polycomb Complexes for Spreading along the Inactive X. Mol. Cell 74, 101-117.e10 (2019).

30. Jeon, Y. \& Lee, J. T. YY1 Tethers Xist RNA to the inactive X nucleation center. Cell 146, 119-133 (2011).

31. da Rocha, S. T. et al. Jarid2 Is Implicated in the Initial Xist-Induced Targeting of PRC2 to the Inactive X Chromosome. Mol. Cell 53, 301-316 (2014).

32. Ridings-Figueroa, R. et al. The nuclear matrix protein $\mathrm{CIZ1}$ facilitates localization of Xist RNA to the inactive X-chromosome territory. Genes Dev. 31, 876-888 (2017).

33. Sunwoo, H., Colognori, D., Froberg, J. E., Jeon, Y. \& Lee, J. T. Repeat E anchors Xist RNA to the inactive $X$ chromosomal compartment through CDKN1A-interacting protein (CIZ1). Proc. Natl. Acad. Sci. U. S. A. 114, 10654-10659 (2017).

34. Lee, H. J. et al. En bloc and segmental deletions of human XIST reveal X chromosome inactivation-involving RNA elements. Nucleic Acids Res. 47, 3875-3887 (2019).

35. Nesterova, T. B. et al. Systematic allelic analysis defines the interplay of key pathways in $X$ chromosome inactivation. Nat. Commun. 10, (2019).

36. Brockdorff, N. Local tandem repeat expansion in Xist RNA as a model for the functionalisation of ncRNA. Non-coding RNA 4, (2018).

37. Van Nostrand, E. L. et al. Robust transcriptome-wide discovery of RNA-binding protein binding sites with enhanced CLIP (eCLIP). Nat. Methods 13, 508-514 (2016).

38. Pintacuda, G. et al. hnRNPK Recruits PCGF3/5-PRC1 to the Xist RNA B-Repeat to Establish Polycomb-Mediated Chromosomal Silencing. Mol. Cell 68, 955-969.e10 (2017).

39. Sprague, D. et al. Nonlinear sequence similarity between the Xist and Rsx long noncoding RNAs suggests shared functions of tandem repeat domains. RNA 25, 1004-1019 (2019).

40. Blondel, V. D., Guillaume, J. L., Lambiotte, R. \& Lefebvre, E. Fast unfolding of communities in large networks. J. Stat. Mech. Theory Exp. 2008, (2008).

41. Bastian, M., Heymann, S. \& Jacomy, M. Gephi : An Open Source Software for Exploring and Manipulating Networks Visualization and Exploration of Large Graphs. Int. AAAI Conf. Weblogs Soc. Media 361-362 (2009). doi:10.13140/2.1.1341.1520

42. Moindrot, B. et al. A Pooled shRNA Screen Identifies Rbm15, Spen, and Wtap as Factors Required for Xist RNA-Mediated Silencing. Cell Rep. 12, 562-572 (2015).

43. Ciaudo, C. et al. Nuclear mRNA degradation pathway(s) are implicated in Xist regulation and X chromosome inactivation. PLoS Genet. 2, 0874-0882 (2006).

44. Sakaguchi, T. et al. Control of Chromosomal Localization of Xist by hnRNP U Family Molecules. Developmental Cell 39, 11-12 (2016). 
45. Patil, D. P. et al. M6 A RNA methylation promotes XIST-mediated transcriptional repression. Nature 537, 369-373 (2016).

46. Xiao, R. et al. Pervasive Chromatin-RNA Binding Protein Interactions Enable RNA-Based Regulation of Transcription. Cell 178, 107-121.e18 (2019).

47. Banani, S. F. et al. Compositional Control of Phase-Separated Cellular Bodies. Cell 166, 651-663 (2016).

48. Yap, K. et al. A Short Tandem Repeat-Enriched RNA Assembles a Nuclear Compartment to Control Alternative Splicing and Promote Cell Survival. Mol. Cell 72, 525-540.e13 (2018).

49. Rayman, J. B., Karl, K. A. \& Kandel, E. R. TIA-1 Self-Multimerization, Phase Separation, and Recruitment into Stress Granules Are Dynamically Regulated by Zn 2+. Cell Rep. 22, 59-71 (2018).

50. Gallego-Iradi, M. C. et al. N-terminal sequences in matrin 3 mediate phase separation into droplet-like structures that recruit TDP43 variants lacking RNA binding elements. Lab.

Investig. 99, 1030-1040 (2019).

51. Coelho, M. B. et al. Nuclear matrix protein Matrin3 regulates alternative splicing and forms overlapping regulatory networks with PTB . EMBO J. 34, 653-668 (2015).

52. Attig, J. et al. Heteromeric RNP Assembly at LINEs Controls Lineage-Specific RNA Processing. Cell 174, 1067-1081.e17 (2018).

53. Long, J. C. \& Caceres, J. F. The SR protein family of splicing factors: Master regulators of gene expression. Biochemical Journal 417, 15-27 (2009).

54. De, I. et al. The RNA helicase Aquarius exhibits structural adaptations mediating its recruitment to spliceosomes. Nat. Struct. Mol. Biol. 22, 138-144 (2015).

55. Rigo, F. et al. Synthetic oligonucleotides recruit ILF2/3 to RNA transcripts to modulate splicing. Nature Chemical Biology 8, 555-561 (2012).

56. Sugimoto, N. et al. Cdt1-binding protein GRWD1 is a novel histone-binding protein that facilitates MCM loading through its influence on chromatin architecture. Nucleic Acids Res. 43, 5898-5911 (2015).

57. Hein, M. Y. et al. A Human Interactome in Three Quantitative Dimensions Organized by Stoichiometries and Abundances. Cell 163, 712-723 (2015).

58. Dominguez, D. et al. Sequence, Structure, and Context Preferences of Human RNA Binding Proteins. Mol. Cell 70, 854-867.e9 (2018).

59. Xue, Y. et al. Genome-wide Analysis of PTB-RNA Interactions Reveals a Strategy Used by the General Splicing Repressor to Modulate Exon Inclusion or Skipping. Mol. Cell 36, 996- 
1006 (2009).

60. Uemura, Y. et al. Matrin3 binds directly to intronic pyrimidine-rich sequences and controls alternative splicing. Genes to Cells 22, 785-798 (2017).

61. Meyer, C. et al. The TIA1 RNA-Binding Protein Family Regulates EIF2AK2-Mediated Stress Response and Cell Cycle Progression. Mol. Cell 69, 622-635.e6 (2018).

62. Banani, S. F., Lee, H. O., Hyman, A. A. \& Rosen, M. K. Biomolecular condensates: Organizers of cellular biochemistry. Nature Reviews Molecular Cell Biology 18, 285-298 (2017).

63. Cerase, A. et al. Phase separation drives X-chromosome inactivation: a hypothesis. Nat. Struct. Mol. Biol. 26, 331-334 (2019).

64. Uszczynska-Ratajczak, B., Lagarde, J., Frankish, A., Guigó, R. \& Johnson, R. Towards a complete map of the human long non-coding RNA transcriptome. Nature Reviews Genetics 19, 535-548 (2018).

65. Giannetti, C. A., Busan, S., Weidmann, C. A. \& Weeks, K. M. SHAPE Probing Reveals Human rRNAs Are Largely Unfolded in Solution. Biochemistry 58, 3377-3385 (2019).

66. Busan, S., Weidmann, C. A., Sengupta, A. \& Weeks, K. M. Guidelines for SHAPE Reagent Choice and Detection Strategy for RNA Structure Probing Studies. Biochemistry 58, 26552664 (2019).

67. Sengupta, A., Rice, G. M. \& Weeks, K. M. Single-molecule correlated chemical probing reveals large-scale structural communication in the ribosome and the mechanism of the antibiotic spectinomycin in living cells. PLoS Biol. 17, (2019).

68. Busan, S. \& Weeks, K. M. Accurate detection of chemical modifications in RNA by mutational profiling (MaP) with ShapeMapper 2. RNA 24, 143-148 (2018).

69. Reuter, J. S. \& Mathews, D. H. RNAstructure: Software for RNA secondary structure prediction and analysis. BMC Bioinformatics 11, (2010).

70. R Development Core Team, R. R: A Language and Environment for Statistical Computing. $R$ Foundation for Statistical Computing 1, (2011).

71. DeLano, W. . . Pymol: An open-source molecular graphics tool. Newsletter On Protein Crystallography (2002).

72. Darty, K., Denise, A. \& Ponty, Y. VARNA: Interactive drawing and editing of the RNA secondary structure. Bioinformatics 25, 1974-1975 (2009).

73. Edgar, R. C. MUSCLE: Multiple sequence alignment with high accuracy and high throughput. Nucleic Acids Res. 32, 1792-1797 (2004).

74. Altschul, S. F., Gish, W., Miller, W., Myers, E. W. \& Lipman, D. J. Basic local alignment 
search tool. J Mol Biol 215, 403-410 (1990).

75. Bailey, T. L. \& Elkan, C. Fitting a mixture model by expectation maximization to discover motifs in biopolymers. Proc. Second Int. Conf. Intell. Syst. Mol. Biol. 2, 28-36 (1994).

76. Grant, C. E., Bailey, T. L. \& Noble, W. S. FIMO: Scanning for occurrences of a given motif. Bioinformatics 27, 1017-1018 (2011). 


\section{METHODS}

\section{Cell culture}

Adherent mammalian cells used in chemical probing experiments, either SM33 ${ }^{27}$ or HEK293 cells, were grown to $80-90 \%$ confluency in either 6-well plates (for targeted priming) or 10-cm dishes (for RNA antisense pulldown). HEK293 cells were cultured in DMEM with 10\% FBS. SM33 cells were cultured in embryonic stem cell media [DMEM high glucose with sodium pyruvate, 15 \% FBS, $0.1 \mathrm{mM}$ non-essential amino acids (Gibco), $2 \mathrm{mM}$ L-glutamine, $0.1 \mathrm{mM} \beta$ mercaptoethanol,1000 U/mL leukemia inhibitory factor (ESGRO, Millipore Sigma)]. Cultures were grown with $100 \mathrm{U} / \mathrm{mL}$ penicillin and $100 \mu \mathrm{g} / \mathrm{mL}$ streptomycin. To induce expression of the Xist RNA, SM33 cells were supplemented with $2 \mu \mathrm{g} / \mathrm{mL}$ doxycycline 16 hours before treatment. For all experiments when performing biological replicates, chemical probing and sequencing library preparation were performed on distinct populations of cells on different days.

\section{In-cell crosslinking with SDA}

For 6-well plates, cells were washed once in $1 \mathrm{~mL}$ PBS, then covered with $900 \mu \mathrm{L}$ PBS. To these cells, $100 \mu \mathrm{L}$ of $100 \mathrm{mM}$ SDA (NHS-diazirine, succinimidyl 4,4'-azipentanoate, Thermo Fisher) in DMSO was added with concurrent manual mixing. For controls, $100 \mu \mathrm{L}$ of neat DMSO was added. Cells were treated with SDA for 10 minutes in the dark at $37^{\circ} \mathrm{C}$, then excess SDA was quenched with a $1 / 9 \times$ volume of $1 \mathrm{M}$ Tris- $\mathrm{HCl}$, pH $8.0(111 \mu \mathrm{L})$. For SM33 cells, which remained adherent during treatment, quenching was performed for 5 minutes in the dark at $37^{\circ} \mathrm{C}$. For HEK293 cells, which detached upon treatment, cells were pelleted at $1000 \times \mathrm{g}$ for 3 minutes immediately after addition of quencher. Cells were washed once with PBS (and pelleted again if not adherent) and then resuspended in $400 \mu \mathrm{L}$ of PBS in a well of a 6 -well plate. To crosslink labeled proteins to RNAs, SDA-treated and untreated cells were placed on ice and exposed to 3 $\mathrm{J} / \mathrm{cm}^{2}$ of $365 \mathrm{~nm}$ wavelength ultraviolet light (about 9 minutes in a UVP CL1000 equipped with five 8-Watt F8T5 black lights) at a distance of 4 inches from the light source. When the amount of SDA used for treatment, the amount of UV light exposure, or the compound used for crosslinking was varied no other changes were made to the procedure. When performing crosslinking procedure on cells grown in $10 \mathrm{~cm}$ dishes, reagent volumes used were multiplied by a factor of five relative to the 6-well procedure. 
Cellular fractionation and proteinase $\mathrm{K}$ lysis of SDA-treated cells

Crosslinked cells were pelleted at $1500 \times \mathrm{g}$ for 5 minutes at $4{ }^{\circ} \mathrm{C}$, washed once in cold PBS and pelleted again, and resuspended in cytoplasmic lysis buffer [10 mM KCl, $1.5 \mathrm{mM} \mathrm{MgCl}_{2}, 20 \mathrm{mM}$ Tris- $\mathrm{HCl}$ (pH 8.0), $1 \mathrm{mM}$ DTT, $0.1 \%$ Triton X-100]. Cells were lysed for 10 minutes at $4{ }^{\circ} \mathrm{C}$ with agitation. Nuclei were pelleted at $1500 \times \mathrm{g}$ for 5 minutes at $4{ }^{\circ} \mathrm{C}$, and cytoplasmic lysates were separated into new tubes. Nuclei were washed once in low-salt solution [10 mM KCl, $1.5 \mathrm{mM}$ $\mathrm{MgCl}_{2}, 20 \mathrm{mM}$ Tris- $\mathrm{HCl}$ (pH 8.0), $1 \mathrm{mM} \mathrm{DTT}$, incubated with agitation at $4{ }^{\circ} \mathrm{C}$ for 2 minutes, pelleted again, and then resuspended in proteinase $\mathrm{K}$ lysis buffer [40 mM Tris- $\mathrm{HCl}(\mathrm{pH} 8.0), 200$ $\mathrm{mM} \mathrm{NaCl}, 20 \mathrm{mM}$ EDTA, 1.5\% SDS, $0.5 \mathrm{mg} / \mathrm{mL}$ proteinase $\mathrm{K}$ ]. Components were added to cytoplasmic lysates to adjust to proteinase $\mathrm{K}$ lysis buffer concentrations. For samples from 6-well plates, $500 \mu \mathrm{L}$ of cytoplasmic lysis buffer and $500 \mu \mathrm{L}$ of proteinase $\mathrm{K}$ lysis buffer were used; 2.5 $\mathrm{mL}$ of each were used for $10-\mathrm{cm}$ dish samples. Nuclear and cytoplasmic fractions were incubated for 2 hours at $37^{\circ} \mathrm{C}$ with intermittent mixing. Nucleic acid was recovered through two extractions with 1 volume of 25:24:1 phenol:chloroform:isoamyl alcohol (PCA) and two extractions with 1 volume of chloroform.

\section{Control SDA treatment of protein-free RNA extracted from cells}

SM33 cells in 10-cm dishes were washed once in $5 \mathrm{~mL}$ PBS, then lysed in $2.5 \mathrm{~mL}$ proteinase $\mathrm{K}$ lysis buffer at $23^{\circ} \mathrm{C}$ for 45 minutes. Nucleic acid was recovered through two extractions with 1 volume of PCA and two extractions with 1 volume of chloroform, and the resulting solution was buffer exchanged into PBS (PD-10 columns, GE Healthcare). The nucleic acid solution was incubated at $37^{\circ} \mathrm{C}$ for 20 minutes before splitting into two equal volume portions ( $1.75 \mathrm{~mL}$ each). To one portion, a $1 / 9$ volume of $100 \mathrm{mM}$ SDA in DMSO was added, and a 1/9 volume of neat DMSO was added to the other. Each sample was incubated at $37^{\circ} \mathrm{C}$ for 10 minutes in the dark. Each sample was spread evenly over a new $10-\mathrm{cm}$ dish, placed on ice, and exposed to $3 \mathrm{~J} / \mathrm{cm}^{2}$ of $365 \mathrm{~nm}$ wavelength ultraviolet light.

\section{In-cell treatment with 5NIA SHAPE reagent}

SM33 mouse embryonic stem cells were grown in 6-well plates. In-cell 5NIA treatment proceeded as described $^{66}$. Cells were washed once in PBS, then covered with $900 \mu \mathrm{L}$ serum-free embryonic stem cell media. To these cells, $100 \mu \mathrm{L}$ of $250 \mathrm{mM}$ 5-nitroisatoic anhydride (5NIA, Astatech) in anhydrous DMSO was added with concurrent manual mixing. For controls, $100 \mu \mathrm{L}$ of neat DMSO was added instead. Cells were treated with $5 \mathrm{NIA}$ for 10 minutes at $37^{\circ} \mathrm{C}$, cells were washed once 
with $1 \mathrm{~mL}$ of PBS, then RNA was harvested from cells with TRIzol (Invitrogen) according to manufacturer's specifications.

\section{NIA treatment of cell-extracted RNA}

SM33 cells on 10-cm dishes were washed once in ice-cold PBS and resuspended in $2.5 \mathrm{~mL}$ icecold lysis buffer [40 mM Tris- $\mathrm{HCl}$ (pH 8.0), $25 \mathrm{mM} \mathrm{NaCl}, 6 \mathrm{mM} \mathrm{MgCl}_{2}, 1 \mathrm{mM} \mathrm{CaCl}_{2}, 256 \mathrm{mM}$ sucrose, 0.5\% Triton X-100, 1000 Units/mL RNasin (Promega), 450 Units/mL DNase I (Roche)]. Cells were lysed for 5 minutes at $4{ }^{\circ} \mathrm{C}$ with agitation. Nuclei were pelleted at $1500 \times \mathrm{g}$ for 5 minutes at $4{ }^{\circ} \mathrm{C}$, resuspended in $2.5 \mathrm{~mL}$ of proteinase $\mathrm{K}$ digestion buffer, and incubated for 45 minutes at $23{ }^{\circ} \mathrm{C}$ with agitation. RNA was extracted twice with one volume of PCA that had been pre-equilibrated with $1.1 \times$ folding buffer [111 mM HEPES $(\mathrm{pH} 8.0), 111 \mathrm{mM} \mathrm{NaCl}, 5.55 \mathrm{mM}$ $\mathrm{MgCl}_{2}$ ], followed by two extractions with one volume of chloroform. RNA was buffer exchanged into $1.1 \times$ folding buffer over a desalting column (PD-10, GE Healthcare). After incubating for 20 minutes at $37^{\circ} \mathrm{C}$, RNA solution was split into two equal portions: One was added to a 1/9 volume of $250 \mathrm{mM} 5 \mathrm{NIA}$ in DMSO, and the other was added to a $1 / 9$ volume of neat DMSO. Both portions were incubated for 10 minutes at $37^{\circ} \mathrm{C}$.

\section{In-cell crosslinking with photo-lysine}

HEK293 cells in 6-well plates at $\sim 60 \%$ confluency were washed once with PBS and then cultured for 16 additional hours in media with either $2 \mathrm{mM}$ natural lysine or $2 \mathrm{mM}$ photo-lysine (Medchem Express). Cells were then crosslinked on ice with $10 \mathrm{~J} / \mathrm{cm}^{2}$ of $365 \mathrm{~nm}$ wavelength UV light. Cells were washed once in PBS, pelleted at $1500 \times \mathrm{g}$, and resuspended in proteinase $\mathrm{K}$ lysis buffer. Proteins were digested for 2 hours at $37^{\circ} \mathrm{C}$. Nucleic acid was recovered through two extractions with 1 volume of PCA and two extractions with 1 volume of chloroform.

\section{RNA precipitation and DNase treatment}

Nucleic acids, including those treated after extraction from cells and those collected by Trizol or PCA after in-cell treatments, were precipitated by addition of a 1/25 volume of $5 \mathrm{M} \mathrm{NaCl}$ and 1 volume of isopropanol, incubation for 10 minutes at $23^{\circ} \mathrm{C}$, and centrifugation at $10,000 \times \mathrm{g}$ for 10 minutes. The precipitate was washed once in $75 \%$ ethanol and pelleted by centrifugation at 7500 $\times \mathrm{g}$ for 5 minutes. Pellets from 6 -well plates were resuspended in $50 \mu \mathrm{L}$ of $1 \times \mathrm{DNase}$ buffer and incubated with 2 units of DNase (TURBO, Thermo Fisher) at $37^{\circ} \mathrm{C}$ for 1 hour. After the first incubation, 2 more units of TURBO DNase were added, and samples were incubated at $37^{\circ} \mathrm{C}$ for 1 hour. Volumes were doubled for samples derived from $10-\mathrm{cm}$ dishes. RNA was purified with 
Mag-Bind TotalPure NGS SPRI beads (Omega Bio-tek): A 1.8× volume of beads was added to DNase reactions and incubated $23^{\circ} \mathrm{C}$ for 5 minutes followed by magnetic separation for 2 minutes. The solution was discarded, and beads were washed three times with $70 \%$ ethanol. RNA was eluted into $30 \mu \mathrm{L}$ of nuclease-free water.

\section{Antisense-mediated purification of Xist and XIST}

In $50 \mu \mathrm{L}$ of nuclease-free water, $10 \mu \mathrm{g}$ of total nuclear RNA (from SM33 or HEK293 cells) was heated at $70{ }^{\circ} \mathrm{C}$ for 5 minutes and then immediately placed on ice for 2 minutes. To the RNA, 100 $\mu \mathrm{L}$ of $1.5 \times$ hybridization buffer [15 mM Tris-HCl (pH 7.0), $7.5 \mathrm{mM}$ EDTA, $750 \mathrm{mM} \mathrm{LiCl,} \mathrm{0.15 \%}$ Triton X-100, $6 \mathrm{M}$ urea], prewarmed to $55^{\circ} \mathrm{C}$, was added. RNA was pre-cleared for 15 minutes at $55^{\circ} \mathrm{C}$ with $15 \mu \mathrm{L}$ of streptavidin-conjugated magnetic beads (Dynabeads MyOne Streptavidin C1, Thermo Fisher) that were pre-washed and resuspended in $1 \times$ hybridization buffer. After magnetic separation, the pre-cleared supernatant was retained. Biotinylated antisense RNA capture probes $^{27}$ (Guttman laboratory Caltech), specific to either mouse Xist or human XIST, were heated at $70{ }^{\circ} \mathrm{C}$ for 5 minutes, cooled on ice for 2 minutes, then diluted in $1 \times$ hybridization buffer. Each pre-cleared RNA sample was mixed with $72 \mathrm{ng}$ of capture probes, and mixtures were incubated at $55^{\circ} \mathrm{C}$ for 80 minutes with shaking. After probe hybridization, $30 \mu \mathrm{L}$ of streptavidin magnetic beads, pre-washed and resuspended in $1 \times$ hybridization buffer, were added to RNA-probe mixtures, and incubation was continued at $55^{\circ} \mathrm{C}$ with shaking for 20 minutes. Beads were captured by magnetic separation and washed twice with $200 \mu \mathrm{L}$ of $1 \times$ hybridization buffer for 5 minutes each at $55^{\circ} \mathrm{C}$. Beads were resuspended in $60 \mu \mathrm{L}$ of NLS elution buffer $[20 \mathrm{mM}$ Tris- $\mathrm{HCl}$, $\mathrm{pH}$ 8.0, 10 mM EDTA, 2\% N-lauroylsarcosine, $10 \mathrm{mM}$ TCEP]. RNA was eluted from beads with three heating-cooling cycles where the temperature was ramped down from $95^{\circ} \mathrm{C}$ to $4{ }^{\circ} \mathrm{C}$ and up to $95^{\circ} \mathrm{C}$ in 1.5-minutes cycles. Beads were captured and RNA eluates saved. The same beads were then resuspended in $40 \mu \mathrm{L}$ of NLS elution buffer and the elution procedure was repeated; the $40 \mu \mathrm{L}$ eluate was added to the original $60 \mu \mathrm{L}$ eluate. Captured RNA was purified (RNeasy MinElute Cleanup Kits, Qiagen). To reduce non-target RNA in the sample, RNAs were enriched again via a second capture: the procedure was identical to first capture except omitted the preclear step.

In vitro SDA crosslinking of T7-transcribed XIST E region with recombinant proteins The E region of human XIST RNA (nucleotides 11900-13100 of NCBI NR_001564.2) was transcribed from a DNA template using T7 RNA polymerase (MEGAscript, Thermo Fisher), treated with DNase I (TURBO, Thermo Fisher), and purified via denaturing polyacrylamide gel 
electrophoresis. Product RNA was eluted from gels in nuclease-free water for 2 hours at $23^{\circ} \mathrm{C}$ and concentrated with centrifugal filters (Amicon Ultra 10K, Millipore Sigma). Before SDA crosslinking, RNA was heat denatured at $98^{\circ} \mathrm{C}$ for 2 minutes, then cooled on ice for 2 minutes before being diluted to $10 \mathrm{nM}$ in $200 \mu$ of RNP crosslinking buffer [1× PBS (pH 7.4), $1 \mathrm{mM} \mathrm{MgCl}$, $1 \mathrm{mM}$ DTT] containing varying concentrations of recombinant XIST-binding proteins PTBP1, MATR3, or TIA1 (HEK293 recombinant, Origene) or BSA control protein (Millipore Sigma). RNPs were allowed to assemble for 30 minutes at $23^{\circ} \mathrm{C}$. $196 \mu$ l of mixtures were added to $4 \mu \mathrm{l}$ of 100 mM SDA (in DMSO) in wells of a 6-well plate and incubated in the dark for 15 minutes at $23^{\circ} \mathrm{C}$. RNPs were crosslinked with $3 \mathrm{~J} / \mathrm{cm}^{2}$ of $365 \mathrm{~nm}$ wavelength UV light. To digest unbound and crosslinked proteins, reactions were adjusted to $1.5 \%$ SDS, $20 \mathrm{mM}$ EDTA, and $0.5 \mathrm{mg} / \mathrm{ml}$ proteinase $\mathrm{K}$ and incubated for 2 hours at $37^{\circ} \mathrm{C}$. RNA was purified once with $1.8 \times \mathrm{SPRI}$ magnetic beads, purified again over an RNeasy MinElute column (Qiagen), and eluted into $14 \mu$ of nuclease-free water.

\section{MaP reverse transcription}

MaP reverse transcription was performed using a revised protocol as described ${ }^{66,67}$. For smaller RNA targets (U1, RNase P, RMRP), 2 pmol of gene-specific primers were mixed with 500 ng of total nuclear RNA (or unfractionated total RNA when indicated). For MaP reverse transcription of enriched Xist/XIST RNAs or in vitro crosslinked XIST E region, $7 \mu \mathrm{L}$ of final RNA product was mixed with $200 \mathrm{ng}$ of random nonamer DNA oligonucleotides. When performing MaP reverse transcription on ribosomal RNA, $3 \mu \mathrm{g}$ of total cytoplasmic RNA was mixed with $200 \mathrm{ng}$ of random nonamers. To RNA-primer mixes, $20 \mathrm{nmol}$ of dNTPs ( $5 \mathrm{nmol}$ each base) was added (10 $\mu \mathrm{L}$ total volume of RNA, primers, and dNTPs), heated to $70{ }^{\circ} \mathrm{C}$ for 5 minutes, and then immediately placed at $4{ }^{\circ} \mathrm{C}$ for 2 minutes. To this template solution, $9 \mu \mathrm{L}$ of freshly-made $2.22 \times \mathrm{MaP}$ buffer [111 mM Tris- $\mathrm{HCl}$ (pH 8.0), $167 \mathrm{mM} \mathrm{KCl,} 13.3 \mathrm{mM} \mathrm{MnCl}_{2}, 22 \mathrm{mM}$ DTT, 2.22 M betaine] was added, and the mixture was incubated at $25^{\circ} \mathrm{C}$ for 2 minutes. After adding 200 units of SuperScript II reverse transcriptase (Thermo Fisher), reaction mixtures were incubated for 10 minutes at $25^{\circ} \mathrm{C}, 90$ minutes at $42{ }^{\circ} \mathrm{C}$, cycled 10 times between $42{ }^{\circ} \mathrm{C}$ and $50{ }^{\circ} \mathrm{C}$ with each temperature incubation 2-minutes long, and then heated to $70{ }^{\circ} \mathrm{C}$ for 10 minutes to inactivate enzyme. Reverse transcription reactions were buffer exchanged into TE buffer $[10 \mathrm{mM}$ Tris- $\mathrm{HCl}$ (pH 8.0), 1mM EDTA] (Illustra G-50 microspin columns, GE Healthcare). 


\section{Two-step PCR of small RNA MaP libraries}

Small RNA sequencing libraries were generated using a two-step PCR strategy as described ${ }^{66,67}$. Briefly, $3 \mu \mathrm{L}$ of cDNA from the reverse transcription reaction was used as template for step 1 PCR, using 20 cycles of gene-specific PCR (Q5 hot-start polymerase, New England Biolabs): 30 $\mathrm{s}$ at $98^{\circ} \mathrm{C}, 20 \times\left[10 \mathrm{~s}\right.$ at $98^{\circ} \mathrm{C}, 30 \mathrm{~s}$ at gene-specific annealing temperature, $20 \mathrm{~s}$ at $\left.72{ }^{\circ} \mathrm{C}\right], 2 \mathrm{~min}$ at $72^{\circ} \mathrm{C}$. Each set of step 1 primers contained the same added handles to prime step 2 PCR, in which Illumina adapters and multiplex indexing sequences were appended to the libraries. Step 1 PCR products were purified (SPRI beads, Mag-Bind TotalPure NGS, Omega Bio-tek, at a 1× ratio), and $2 \mathrm{ng}$ of product was used as template for step 2 PCR. Step 2 PCR involved $30 \mathrm{~s}$ at 98 ${ }^{\circ} \mathrm{C}, 10 \times\left[10 \mathrm{~s}\right.$ at $98^{\circ} \mathrm{C}, 30 \mathrm{~s}$ at $66^{\circ} \mathrm{C}, 20 \mathrm{~s}$ at $72^{\circ} \mathrm{C}$, and $2 \mathrm{~min}$ at $72{ }^{\circ} \mathrm{C}$. Step $2 \mathrm{PCR}$ products were purified with SPRI beads at a $0.8 \times$ ratio and eluted into $15 \mu \mathrm{L}$ of nuclease-free water.

Second-strand synthesis, fragmentation, and amplification of long RNA MaP libraries For products of randomly primed MaP reverse transcription, buffer-exchanged cDNA was diluted to $68 \mu \mathrm{L}$ with nuclease-free water. Each diluted cDNA was mixed with $8 \mu \mathrm{L}$ of $10 \times$ Second Strand Synthesis Reaction Buffer and $4 \mu \mathrm{L}$ Second Strand Synthesis Enzyme Mix (NEBNext, New England Biolabs), and reactions were incubated at $16{ }^{\circ} \mathrm{C}$ for 2.5 hours. The double-stranded DNA (dsDNA) products were purified with SPRI beads at a $0.8 \times$ ratio to favor longer products and exclude probe-templated products. Products were eluted into $15 \mu \mathrm{L}$ of nuclease-free water. The dsDNA libraries were fragmented, multiplex indexed, and PCR amplified. To fragment libraries from total cytoplasmic RNA, $5 \mu \mathrm{L}$ of $0.2 \mathrm{ng} / \mu \mathrm{L}$ dsDNA was combined with $10 \mu \mathrm{L}$ of Tagment DNA Buffer and $5 \mu \mathrm{L}$ of Amplicon Tagment Mix (Nextera XT DNA Library Prep Kits, Illumina). Mixtures were incubated at $55^{\circ} \mathrm{C}$ for $5 \mathrm{~min}$, then cooled to $10{ }^{\circ} \mathrm{C}$. As soon as the temperature reached 10 ${ }^{\circ} \mathrm{C}, 5 \mu \mathrm{L}$ of NT Buffer (Nextera XT DNA Library Prep Kits, Illumina) was added to neutralize the reaction, which was then incubated at $23^{\circ} \mathrm{C}$ for $5 \mathrm{~min}$. The entire reaction volume was used as a template for PCR with $15 \mu \mathrm{L}$ of Nextera PCR Master Mix and $5 \mu \mathrm{L}$ each of forward and reverse indexing primers (Nextera XT DNA Library Prep Kits, Illumina): $72{ }^{\circ} \mathrm{C}$ for $3 \mathrm{~min}, 95^{\circ} \mathrm{C}$ for $30 \mathrm{~s}, 12$ $\times\left[95^{\circ} \mathrm{C}\right.$ for $10 \mathrm{~s}, 55^{\circ} \mathrm{C}$ for $30 \mathrm{~s}, 72^{\circ} \mathrm{C}$ for $\left.30 \mathrm{~s}\right]$, and $72{ }^{\circ} \mathrm{C}$ for 5 minutes. The final PCR products were purified with SPRI beads at a $0.65 \times$ ratio and eluted into $15 \mu \mathrm{L}$ of nuclease-free water. For low concentration Xist and XIST capture libraries, $8 \mu \mathrm{L}$ of capture product was fragmented with only $2 \mu \mathrm{L}$ of Amplicon Tagment Mix, the concentration of index primers was halved during PCR, and PCR cycles were increased to 20 . 


\section{Sequencing of MaP libraries}

Size distributions and purities of amplicon and randomly primed libraries were verified (2100 Bioanalyzer, Agilent). Step 2 amplicon libraries (about 120 amol of each) were sequenced on a MiSeq instrument (Illumina) with $2 \times 150$ or $2 \times 250$ paired-end sequencing, depending on the length of the RNA target. Libraries derived from total cytoplasmic RNA were sequenced with $2 \times$ 300 paired-end sequencing on a MiSeq instrument, combining reads from multiple runs until desired ribosomal RNA sequencing depth was achieved. Xist and XIST capture libraries were sequenced to desired depth via a combination of $2 \times 300$ paired-end runs on a MiSeq and $2 \times$ 150 paired-end runs on a NextSeq 500 instrument.

\section{Mutation counting and SHAPE profile generation with ShapeMapper 2 software}

FASTQ files from sequencing runs, with the exception of capture libraries, were directly input into the ShapeMapper 2 software ${ }^{68}$ for read alignment and mutation counting. To ensure mutation rates were not affected by reduced fidelity at reverse transcription initiation sites, reads from capture libraries were trimmed by 14 nucleotides (primer length $+5 \mathrm{nts}$ ) after adapter sequences on each end. To accomplish this step for amplicon libraries, target FASTA files input to ShapeMapper 2 had primer-overlapping sequences and the first 5 nucleotides transcribed in RT set to lowercase, which eliminates these positions from analysis. To expedite analysis of long RNAs like Xist/XIST, corresponding FASTQs were split into $\sim 10$ subsets and run in multiple parallel ShapeMapper 2 instances before having their outputs recombined into single profiles. ShapeMapper 2 was run with --min-depth 5000 and --output-classified flags with all other values set to defaults. In an RNP-MaP experiment, the SDA+UV-treated samples are passed as the "modified" samples and UV-only treated samples as "unmodified" samples. The outputs "profile.txt", "parsed.mut”, and “.map" files are required for RNP-MaP site, RNP-MaP correlation, and SHAPE analyses.

\section{Identification of low SHAPE, low Shannon entropy regions of Xist and XIST using SuperFold} The SuperFold analysis software ${ }^{13}$ was used with in-cell and cell-extracted 5NIA experimental SHAPE data from mouse Xist and human XIST to inform RNA structure modeling by RNAStructure ${ }^{69}$. Default parameters were used to generate base-pairing probabilities for all nucleotides (with a max pairing distance of $600 \mathrm{nt}$ ), Shannon entropies for each nucleotide, and minimum free energy structure models. 


\section{$\triangle$ SHAPE of mouse RNase $P$ and Rmrp}

Normalized SHAPE reactivities for 5NIA-treated mouse RNase $P$ and Rmrp RNAs were compared between in-cell treated samples and those treated after cell extraction using the $\triangle$ SHAPE program ${ }^{15}$. Default parameters were used, and the $5^{\prime}$ primer sequence, the $3^{\prime}$ primer sequence, and the first 5 nucleotides transcribed during the reverse transcription step were all masked to exclude them from analysis. Only nucleotides that passed the included Z-factor and standard score significance testing were mapped as $\triangle$ SHAPE sites.

\section{Post-processing of mutation frequencies into RNP-MaP reactivities}

Per-nucleotide mutation frequencies (number of mutation events/effective read depth) for both crosslinked (SDA+UV-treated) and uncrosslinked (UV-treated) samples were calculated from output ShapeMapper 2 profiles. RNP-MaP "Reactivity" was computed as the ratio of nucleotide crosslinked mutation frequency to uncrosslinked mutation frequency (SDA+UV rate/UV only rate). Exceptions are in Figure 1C and S1, where "Reactivity" refers to the ratio with a no treatment control as the denominator (treatment rate/no treatment rate). To be designated as RNP-MaP sites, nucleotide positions had to pass three quality filters: (1) sites were required to have at least 50 more mutation events in the SDA+UV-treated sample than the UV-treated sample; (2) site reactivities had to exceed the nucleotide-dependent empirical thresholds described in the next section; and (3) nucleotide reactivities were required to achieve a Z-factor greater than zero. .

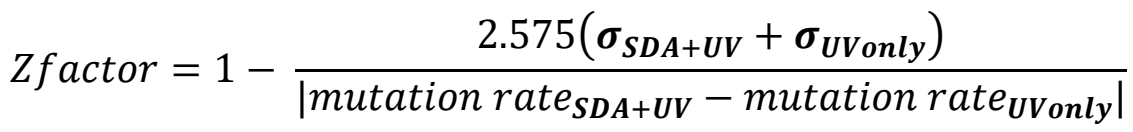

$$
\begin{aligned}
& \text { where } \boldsymbol{\sigma}_{\boldsymbol{n} \boldsymbol{t}}=\sqrt{\text { mutation rate }_{n t}} / \sqrt{\text { reads }_{n t}}
\end{aligned}
$$

\section{Empirical derivation of RNP-MaP site nucleotide reactivity thresholds}

Two biological replicates of RNP-MaP were performed on human U1 snRNA, RNase P RNA, and $18 \mathrm{~S}$ and $28 \mathrm{~S}$ rRNAs, each a part of RNA-protein complexes where atomic resolution structural data is available, enabling separation of nucleotides into two groups: those within $10 \AA$ of protein $(<10 \AA)$ and those further than $10 \AA$ from protein $(>10 \AA)$. For U1 snRNA, the binding site of the SNUPN protein has been mapped by crosslinking and mass spectrometry ${ }^{18}$, and distances between the three nucleotides surrounding the crosslink site and nearest amino acids were assumed to be less than $4 \AA$. For each RNA replicate, reactivities were further grouped by nucleotide identity (U, A, C, and G). The $90 \%$ reactivity value of nucleotides in a $>10 \AA$ group were set as background thresholds $\left(B G_{x>10}\right)$ and compared to the median $\left(M E D_{\text {all }} \mathrm{x}\right)$ and standard 
deviations $\left(S D_{\text {all }} \mathrm{x}\right.$ ) of reactivities for all nucleotides included in both $<10 \AA$ and $>10 \AA$ groups to create relative threshold factors $\left(T_{X}\right)$ :

$$
T_{X}=\frac{\left(B G_{X>10}-M E D_{\text {all } X}\right)}{S D_{\text {all } X}}, \text { where } X \text { is } U, A, C \text {, or } G
$$

Relative threshold factors for each nucleotide from all eight replicates of the four RNAs were then averaged together, weighted by the number of nucleotides measured in each RNA, to obtain final empirically derived nucleotide relative threshold factors: 0.59 for $U, 0.29$ for $A, 0.93$ for $C$, and 0.78 for $\mathrm{G}$. These factors represent the number of standard deviations from the median of nucleotide reactivity that must be achieved to be considered an RNP-MaP site. Factors can be applied to any RNA: to get exact nucleotide thresholds for an RNP-MaP experiment, the median reactivities for each nucleotide group $(U, A, C$, or $G)$ are multiplied by their corresponding threshold factors. Factors were calculated from existing comprehensive datasets, however including more data from other RNPs or improving upon existing atomic resolution RNP structures could increase the precision of these threshold factors in the future.

\section{Graphical display of RNP-MaP Reactivities and crosslinking sites}

Violin plots representing distributions of RNP-MaP reactivities were generated using the vioplot package in $\mathrm{R}$ through the web tool BoxPlotR ${ }^{70}$. RNP-MaP crosslinking sites were superimposed onto atomic resolution structure models using $\mathrm{PyMol}^{71}$. Secondary structure projection images were generated using the (VARNA) visualization applet for RNA ${ }^{72}$.

\section{RNP-MaP correlation analysis}

Correlations between RNP-MaP sites were computed over 3-nucleotide windows using a previously described G-test framework (RingMapper) ${ }^{19}$. Windows were required to be separated by $>4$ nucleotides, jointly covered by more than 10,000 sequencing reads, jointly co-mutated $>50$ times, and have background mutation rates below 6\% (Fig. S2). Pairs of windows exhibiting Gtest statistics $>20\left(P<10^{-5}\right)$ in the SDA+UV treated sample and $G<10.83(P>0.001)$ in the UVonly sample were determined to be significantly correlated. Current technical limitations of MaP reverse transcription processivity (500-600 nucleotides) and sequencing instrument clustering (< 1000 nucleotides) limit distances of readily measured correlations to $<500$ nucleotides. 


\section{RNase $P$ and RMRP structural alignment}

Corresponding helices, loops, and intervening regions in RNase P and RMRP RNAs were separated into structural domains (Fig. 3) and separately aligned with MUSCLE ${ }^{73}$. Region alignments were recombined to create the final alignment (Supplemental File 1).

Calculation of XistXIST RNP-MaP site, correlation strength, and eCLIP site densities To calculate the RNP-MaP site density for Xist and XIST (Fig. 4a and S8), nucleotides whose reactivities were in the top $5 \%$ of all reactivities (U, A, C, and G nucleotides evaluated separately) were identified. Site density was defined as the number of nucleotides in a centered 51 nucleotide window that were top 5\% sites. Correlation strength density was defined as the sum of the mutual information of all nucleotides within the window normalized to (i.e., divided by) the read depth of the central nucleotide. We selected high confidence eCLIP sites $^{37}$ (Supplemental File 2) within XIST that passed Irreproducible Discovery Rate thresholds (see www.encodeproject.org/eclip), meaning that sites were defined by signal peaks of similar amplitude in both eCLIP replicates. The eCLIP site density (Fig. 4b) was defined as the total number of observed eCLIP sites within the 51-nucleotide window. For densities in Fig. 6, Fig. S9, and Fig. S10, all RNP-MaP sites were included (because signal only comes from a single protein) and centered nucleotide windows were shortened to 25 long (since the E region is only $1200 \mathrm{nts}$ ).

Identification of conserved sequence regions between mouse Xist and human XIST

To identify and rank areas of significant conservation between mouse Xist (NCBI NR_001463.3) and human XIST (NCBI NR_001564.2) RNA sequences, we performed a local alignment $\left(B L A S T n^{74}\right)$ and retained all segments with E-values above 0 and with lengths $>100$ nucleotides and ranked these segments by alignment bitscore.

\section{Network analysis of XIST RNP-MaP correlation-linked eCLIP sites}

To create a list of protein-linking correlations, we first counted the number of times nucleotides within our high confidence eCLIP sites were correlated in RNP-MaP data (links) and measured the summed total of mutual information within links. To ensure that links were not simply a product of eCLIP site number and proximity or the average length and density of RNP-MaP correlations, we randomly shuffled the location of RNP-MaP correlations and counted links achieved between protein pairs iteratively 2000 times, generating p-values for each protein pairing based on the number of links between them and the strength of those links (Table S1). Resulting links between protein pairs with $p$-values less than 0.05 were then used as edges 
connecting nodes (proteins) on a network map (Fig. 5). A maximum modularity of the network (0.419), weighted by the strengths of included links (mutual information) and without changing resolution, was calculated using Gephi ${ }^{41}$, and node sizes were adjusted manually to convey indicated relationships.

\section{Identification of RNP-MaP enriched motifs in the XIST E region}

MEME ${ }^{75}$ was used to identify motifs enriched by RNP-MaP in vitro. We first expanded each RNPMaP nucleotide into 9-mer sites (extending by 4 on either side). Overlapping sites were combined iteratively until no overlapping sequences remained. Combined sites were used as MEME input in classic mode using a 0-order model of sequences, allowing for any number of motif repetitions in each sequence, and explicitly looking for five 9-mer motifs. The top two motifs were retained for each in vitro experiment, and locations of all matching motifs in XIST E region were found using $\mathrm{FIMO}^{76}$ with a p-value threshold of $10^{-3}$. For the in-cell experiment, only sites from the $\mathrm{E}$ region were considered in MEME, and the first and fourth most significant motif (class 2 and class 1 , respectively) were included in Fig. 6, S9, and $\mathbf{S 1 0 .}$

\section{XIST RNA reporter plasmid design}

To create XIST region-containing reporters, we used inverse PCR and re-ligation to insert a multiple cloning site into the $3^{\prime}$ end of the pNL 3.2.CMV vector (Promega) between Xbal and Fsel sites and to add the second intron from human HBA1 at nucleotide position 196 in the nanoluciferase coding region (native Xist/XIST is spliced in its central region). Plasmids with varying regions of XIST were subcloned into the Xhol and Kpnl restriction sites, and a control plasmid was generated through inverse PCR (Table S2).

\section{Plasmid transfection and purification of XIST reporter RNA for qPCR}

HEK293 cells were plated at 100,000 cells/mL in 2-mL volumes per well of 6 -well plates and then cultured for 24 hours at $37^{\circ} \mathrm{C}$. Each well was then transfected with a mixture of $0.6 \mu \mathrm{g}$ of reporter plasmid and $1.8 \mu \mathrm{L}$ of FuGENE 6 transfection reagent (Promega) in $200 \mu \mathrm{L}$ of serum-free DMEM, and cells were cultured for an additional 48 hours at $37^{\circ} \mathrm{C}$. Transfected cells were pelleted at $1500 \times \mathrm{g}$ for 5 minutes at $4{ }^{\circ} \mathrm{C}$, washed once in cold PBS and pelleted again, and resuspended in $500 \mu \mathrm{L}$ cytoplasmic lysis buffer. Cells were lysed for 10 minutes at $4{ }^{\circ} \mathrm{C}$ with agitation. Nuclei were pelleted at $1500 \times \mathrm{g}$ for 5 minutes at $4{ }^{\circ} \mathrm{C}$, and cytoplasmic lysates were separated into new tubes. Nuclei were washed once in low-salt solution, incubated with agitation at $4{ }^{\circ} \mathrm{C}$ for 2 minutes, pelleted again, and then resuspended in $500 \mu \mathrm{L}$ proteinase $\mathrm{K}$ lysis buffer. $\mathrm{NaCl}$, EDTA, 
SDS, and proteinase $\mathrm{K}$ were added to cytoplasmic lysates up to proteinase $\mathrm{K}$ lysis buffer concentrations. Nuclear and cytoplasmic fractions were incubated for 2 hours at $37^{\circ} \mathrm{C}$ with intermittent mixing. Nucleic acid was recovered through two extractions with 1 volume of 25:24:1 PCA, two extractions with 1 volume of chloroform, and precipitation with $1 / 25$ volume of $\mathrm{NaCl}$ and 1 volume of isopropanol.

qPCR of reporter RNAs from nuclear and cytoplasmic fractions Equal quantities of RNA (30 ng) from each nuclear and cytoplasmic fraction were used generate first-strand cDNA in random hexamer-primed reverse transcription reactions using SuperScript II (Thermo Fisher). Triplicate mixtures of $2.5 \mu \mathrm{L}$ of template cDNA, $2.5 \mu \mathrm{L}$ of $2 \mu \mathrm{M}$ primers, and 12.5 $\mu \mathrm{L}$ of Maxima SYBR Green qPCR Master Mix (Thermo Fisher) in $25 \mu \mathrm{L}$ total reactions were prepared for each sample. Reaction mixtures from matched no-reverse transcriptase controls were also prepared. Primer sets specific to the reporter gene and 18S ribosomal RNA (as a normalization control) were used for each sample fraction. qPCR was performed on a QuantStudio 6 Flex Real-Time PCR System (Thermo Fisher) with steps of 5 min at $95{ }^{\circ} \mathrm{C}, 40$ cycles of [ $15 \mathrm{~s}$ at $95^{\circ} \mathrm{C}, 30 \mathrm{~s}$ at $65^{\circ} \mathrm{C}, 40 \mathrm{~s}$ at $72{ }^{\circ} \mathrm{C}$, and a melt curve to confirm single major products. Fluorescence readings were taken at elongation steps $\left(72^{\circ} \mathrm{C}\right)$. All specific signals were observed more than 8 cycle thresholds earlier (256-fold more signal) than no-reverse transcriptase controls. Signals were averaged across triplicate qPCRs, normalized to $18 \mathrm{~S}$ rRNA signal, then normalized to control reporter signals.

\section{RNA FISH of XIST RNA reporters}

Custom RNA FISH probes antisense to the nanoluciferase mRNA and labeled with Quasar 570 Dye were ordered from LGC Biosearch with design parameters of masking level 5 , oligo length 19 , and minimum spacing length 2). HEK293 cells were plated at a concentration of 10,000 cells $/ \mathrm{mL}$ in wells of a 12-well plate, with each well containing a poly-L-lysine coated \#1.5 coverslip (Neuvitro). After 24 hours of growth, $50 \mu \mathrm{l}$ of transfection mix [20 $\mu \mathrm{l}$ of $15 \mathrm{ng} / \mu \mathrm{l}$ reporter plasmid, $0.9 \mu \mathrm{l}$ of Fugene 6 (Promega), and $79 \mu \mathrm{l}$ of DMEM] was added to cells. At 48 hours posttransfection, each well was washed once with $1 \mathrm{ml}$ PBS, fixed with $1 \mathrm{ml}$ of $3.7 \%$ formaldehyde in PBS for 10 minutes at room temperature, then washed twice with PBS. Cells were permeabilized with $1 \mathrm{ml}$ of $70 \%$ ethanol overnight at $4{ }^{\circ} \mathrm{C}$. After removing ethanol, cells were incubated in wash buffer 1 [20\% Wash Buffer A (LGC Biosearch), 10\% formamide] for 5 minutes at room temperature, and then coverslips were transferred to a humidified chamber with cells facing down onto $100 \mu$ l of hybridization buffer [90\% Stellaris RNA FISH Hybridization Buffer (LGC Biosearch), 
$10 \%$ formamide, $125 \mathrm{nM}$ antisense probes]. After overnight incubation in the dark at $37^{\circ} \mathrm{C}$, coverslips were transferred into 12-well dishes and incubated in $1 \mathrm{ml}$ of wash buffer 1 for 30 minutes at $37{ }^{\circ} \mathrm{C}$ in the dark, then counterstained for 30 minutes at $37^{\circ} \mathrm{C}$ with $5 \mathrm{ng} / \mu \mathrm{DAPI}$ in 1 $\mathrm{ml}$ of wash buffer 1. Coverslips were washed a final time in $1 \mathrm{ml}$ of Wash Buffer B (LGC Biosearch) before being mounted onto a microscope slide with $12 \mu \mathrm{l}$ of Vectashield Mounting Medium (Vector Laboratories) and sealed. RNA FISH z-stack images were captured using a $100 \times / 1.3$ oil objective on an Olympus IX81 Microscope and were deconvoluted using the AutoQuant X software. Z-stacks were collapsed into maximum intensity projections using the Fiji software. 


\section{FIGURE LEGENDS}

Figure 1. RNP-MaP strategy for probing RNA-protein interaction networks in cells. (a) Scheme for selective chemical crosslinking of protein to RNA by SDA. (b) Workflow of the RNPMaP experiment. (c) Relative mutation rate over background [ $\log _{2}$ (reactivity)] of Rrmp RNA with and without SDA, UV, and cellular proteins. (d) $\log _{2}$ (reactivity) of Rmrp RNA in the presence of SDA, pre-quenched SDA, and DA-EtOH. In violin plots shown in panels $C$ and D, circles indicate medians, box limits indicate the first and third quartiles, whiskers extend 1.5 times the interquartile range, and smoothed polygons show data density estimates and extend to extreme values.

\section{Figure 2. RNP-MaP correctly defines protein interaction networks in the U1 snRNP. (a)} Structures surrounding lysine-RNA crosslinking sites (structures from 3CW1 and 4PKD ${ }^{14}$ ). (b) Bar graph of $\log _{2}$ (average reactivity) from two replicate experiments on U1 snRNA in HEK293 cells. RNP-MaP sites passing thresholds are shown in green. Nucleotides within $9 \AA$ of a lysine amine are highlighted with gray boxes above, and black boxes indicate exact locations of structures represented in panel A. RNP-MaP correlations (top 10\% in mutual information strength) are shown as orange arcs. Nucleotides that overlap amplification primers (light gray boxes below) are not observable by RNP-MaP. (c) Secondary structure model of the human U1 RNP emphasizing relative protein positions, RNP-MaP sites, and primer regions.

\section{Figure 3. RNP-MaP reveals conserved protein interaction networks in RNase $P$ and RMRP}

RNAs. (a) Secondary structure of human RNase P and RMRP RNAs with observed RNP-MaP sites identified in experiments in HEK293 cells highlighted in green. Proteins proximal to each site (judged by nearest lysine) are labeled. Important functional domains are indicated, and conserved base-paired structural regions (P\#) are labeled in gray. (b) RNP-MaP correlations for human RNase $P$ and RMRP, plotted on a structure-based sequence alignment. Conserved nucleotide positions and structural domains (P\#) are labeled. Correlations shown are for the top $10 \%$ of mutual information strength. Correlations corresponding to linkages between nucleotides that are present only in one of the RNAs are shown in light shading. (c) The total strength of correlations (by mutual information, MI) at each nucleotide for the human RNase P and RMRP RNAs plotted on the same structure-based alignment. Protein interaction network hubs are labeled. 
Figure 4. RNP-MaP identifies conserved protein interaction networks in the XIST IncRNA. (a) The density of RNP-MaP sites (green, the total number of RNP-MaP sites per 51-nt window, left axis) across the entirety of mouse Xist (top) and human XIST (bottom). Black lines indicate correlation strength densities (depth-normalized mutual information, MI, per 51-nt window, right axis). Highly networked regions within XIST are indicated with orange boxes below graph. Regions with conserved local sequence alignments are highlighted with red shading. Rectangles labeled A-F show locations of tandem repeat arrays within each RNA; filled rectangles denote well-defined repeat sequences, and open rectangles indicate regions identified as homologous in this work, as inferred by RNP-MaP similarity. The D region in human XIST contains a distinct repeat core (black) flanked by more degenerate repetitive elements (gray). Gaps were introduced to align RNAs by conservation and RNP-MaP similarity. Experiments were performed in SM33 and HEK293 cells. (b) Density of eCLIP sites along the human XIST RNA shown as the number of eCLIP sites within 51-nt windows. Based on 151 total sites from 30 proteins mapped reproducibly to XIST in K562 cells ${ }^{37}$.

Figure 5. Communities of XIST-binding proteins. Network graph of protein-bound sites (nodes) from eCLIP data on human XIST RNA linked by RNP-MaP correlations (edges). Relative summed mutual information for correlations linking each protein node to other proteins in its community or to all proteins are shown as filled and open circles, respectively (see key). Summed mutual information of all correlations in an edge and total number of correlations in each edge are indicated by edge color and width, respectively.

Figure 6. PTBP1, MATR3, and TIA1 recognize XIST E region via two binding modes. (a) Density of RNP-MaP sites on human XIST from experiments performed using an RNA spanning the $E$ region and the indicated recombinant proteins (red, purple, blue). Experiment performed on native XIST in HEK293 cells is shown in orange. Locations of eCLIP sites and RNP-MaP enriched motifs corresponding to each protein are shown as thick colored lines and small rectangles, respectively. Enriched motifs are distinguished class 1 (gray) or class 2 (black). RNPMaP densities are the number of RNP-MaP sites observed within a $25 \mathrm{nt}$ window. All densities are on the same scale, with 19 as the maximum density achieved (in-cell). Locations of eCLIP sites for other proteins are shown at bottom. (b) RNP-MaP enriched sequence motifs (by MEME) $)^{75}$ and E-values for each tested protein, shown as position weighted matrices, for class 1 and class 2 motifs. (c) Relative expression levels of reporter RNAs containing non-XIST control, XIST E region, and other highly interactive XIST (by RNP-MaP) sequences, shown for both 
cytoplasmic and nuclear fractions. E region insert includes nts 11900-13100 of XIST. Nucleotide positions in XIST for other inserted protein-interactive sequences are indicated. qPCR signal from reporters were first normalized to $18 \mathrm{~S}$ ribosomal RNA signal in each fraction, and then each reporter signal was normalized to the non-XIST control. Error bars represent standard error of the mean $(n=3)$. All differences between $E$ region reporter and other constructs are significant $(P<$ 0.02) by Student's t-test (two-sided), except for the difference between XIST E and Non-XIST nuclear fractions $(P=0.28)$. (d) XIST E region containing reporters localize in condensed foci (by in situ hybridization, ISH, white arrows) that co-occur with deformed nuclei (by DAPI), while nonXIST control reporter shows diffuse localization pattern with no nuclear deformation. White scale bars indicate distances of $5 \mu \mathrm{m}$.

Figure S1. RNP-MaP signal in living cells is dependent on SDA and UV. (a) Violin plots of $\log _{2}$ (reactivity) for U1 and RNase P RNA for reactions in SM33 cells, with RNA extracted from cells, and in cells without SDA, and without UV. (b) Violin plots of $\log _{2}$ (reactivity) of Rmrp in SM33 cells as functions of SDA and UV doses. When SDA concentration was varied, UV dose was 3 $\mathrm{J} / \mathrm{cm}^{2}$. When UV energy was varied, SDA concentration was $10 \mathrm{mM}$. For violin plots, white circles indicate medians, box limits indicate the first and third quartiles, whiskers extend 1.5 times the interquartile range, and smoothed polygons show data density estimates and extend to extreme values.

Figure S2. RNP-MaP site and correlation determination. Scheme outlining determination of (a) RNP-MaP sites and (b) correlations. For (a), depth threshold and mutation count above background threshold were set to eliminate noise at signal margins. A Z-factor above 0 is achieved only when $99 \%$ confidence intervals of UV only and SDA + UV rates do not overlap. To limit false positives, nucleotide-specific thresholds were set at the levels of highest reactivity among nucleotides distant from proteins in RNPs of known structure (U1, RNase P, 18S, and 28S), expressed as the number of standard deviations from median reactivities of each nucleotide (detailed in methods). For (b) 3 nt windows and $4 \mathrm{nt}$ separations were set to accommodate the size of some longer and more complex mutation and deletion events during MaP reverse transcription. Thresholds of 10,000 depth, $6 \%$ background mutation rate, and 50 comutation events limit noise and false positives. 
Figure S3. RNP-MaP reproducibly discriminates protein-bound nucleotides independent of local RNA structure and nucleotide identity. (a) Correlation (Pearson's $r$ ) between

$\log _{2}$ (reactivity) of nucleotides from biological replicates of RNP-MaP experiments in HEK293 cells on U1, RNase P, RMRP, 18S, and 28S RNAs. is highly reproducible between biological replicates (bottom panels), especially for RNP-MaP sites. Correlations are shown for all nucleotides (blue dots) and RNP-MaP sites (green dots) for all RNAs. The number of nucleotides represented from each RNA is indicated above each graph in parentheses. (b) Nucleotide $\log _{2}$ (reactivity) from RNP-MaP experiments in HEK293 cells for human U1, RNase P, 18S, and 28S RNAs are plotted against distance to protein lysine side chain amines. The significance of the difference between RNP-MaP site (green) and non-site (black) distance distributions is indicated (Mann-Whitney U-test, one-sided). (c) Violin plots of RNP-MaP site nucleotide $\log _{2}$ (reactivity) from experiments in HEK293 cells (18S, 28S, U1, RNase P, RMRP, XIST RNAs) or SM33 cells (Xist RNA), grouped as unpaired nucleotides $(U)$ and paired nucleotides (P). (d) Violin plots of nucleotide $\log _{2}$ (reactivity) from RNP-MaP experiments in HEK293 cells (U1, RNase $P, 18 S$, and 28S RNAs) grouped as protein proximal $(<10 \AA)$ and protein-distant $(>10 \AA)$ nucleotides and separated by nucleobase identity (Uridine, Adenosine, Cytidine, and Guanosine). To obtain nucleobase-specific thresholds (black dotted lines) for consideration as RNP-MaP sites: the standard deviations of reactivity for all of each nucleobase within an experiment are multiplied by corresponding empirically-derived threshold factors $(U-0.59, A-0.29, C-0.93, G-0.78)$, and these products are added to the corresponding nucleobase reactivity medians. For violin plots in panels $\mathrm{c}$ and $\mathrm{d}$, white circles indicate medians, box limits indicate the first and third quartiles, whiskers extend 1.5 times the interquartile range, and smoothed polygons show data density estimates and extend to extreme values.

\section{Figure S4. Orthogonal chemical probing and metabolic labeling approaches corroborate} RNP-MaP. (a) $\triangle$ SHAPE identifies changes in SHAPE reactivity between RNA in cells and in solution, identifying regions of RNA that interact with cellular components, including proteins ${ }^{15}$. Overlap of RNP-MaP and $\triangle$ SHAPE sites are shown on secondary structure diagrams for mouse Rmrp and RNase P RNAs. Of 65 RNP-MaP sites (green shading) in Rmrp and RNase P RNAs, $22(34 \%)$ are $\triangle$ SHAPE sites (lines), and $52(80 \%)$ are within five nucleotides of $\triangle$ SHAPE sites by contact distance (which includes distances across base pairs in the secondary structures). In-cell SHAPE protections (green) and enhancements (purple) are labeled. Primer-binding sequences excluded from analysis are indicated, and solid grey and dotted grey lines indicate pseudoknot helices and predicted tertiary base-pair (inferred from human RNase P structure), respectively. 
(b) Metabolic labeling by photo-lysine incorporates diazirines into native lysine side chains, and these residues can be photo-activated, like SDA, with $365 \mathrm{~nm}$ UV light. A violin plot of $\log _{2}$ (reactivity) shows that photo-lysine is less reactive with RNA than is SDA (left), as it is likely incorporated into proteins with low efficiency, has no linker, and requires a shorter crosslinking distance. White circles indicate medians, box limits indicate the first and third quartiles, whiskers extend 1.5 times the interquartile range, and smoothed polygons show data density estimates and extend to extreme values. Correlation (Pearson's $r$ ) between SDA and photo-lysine reactivity (right) is shown. (c) All photo-lysine reactive regions are also reactive by SDA, as illustrated on secondary structure projections of RMRP.

Figure S5. RNP-MaP interaction networks are highly reproducible. Top $10 \%$ of RNP-MaP correlations by mutual information (arcs) and the per-nucleotide summed mutual information for all RNP-MaP correlations (purple peaks) from two biological replicates in HEK293 cells are plotted by nucleotide position (nt) for human U1, RNase P, and RMRP RNAs.

Figure S6. RNP-MaP sites are conserved between mouse and human RNAs. Locations of RNP-MaP sites are shared between mouse and human homologues of RNase P and RMRP, as illustrated on secondary structure projections of each RNA. Structural domains are labeled in gray, the percent sequence identities between RNAs are indicated, and gray lines denote pseudoknot helices. Proteins in close proximity to each RNP-MaP site on RNase P (based on distance to lysine amine) are labeled in green lettering. Experiments performed in SM33 or HEK293 cells.

Figure S7. Gene-specific and random priming strategies for RNP-MaP library preparation. Schemes outlining generation of RNP-MaP sequencing libraries from (a) small RNA targets and amplicons or (b) long RNA targets are shown. Gene-specific priming is recommended for RNAs or regions of an RNA < 500 nucleotides in length, and enrichment and random priming is suggested for longer RNAs.

Figure S8. RNP-MaP captures protein interaction information across very long non-coding RNAs. (a) Almost all nucleotides in mouse Xist (orange) and human XIST (blue) were observed above 10,000 depth thresholds in RNP-MaP experiments, shown per-nucleotide. Tandem repeat sequence arrays A-F (white boxes with black letters), regions homologous to repeat regions (white letters), the $\mathrm{D}$ region core (white box with thick black outline), and exon-exon junctions 
(thick vertical black lines) are indicated on Xist and XIST. (b) RNP-MaP sites were more frequently observed at adenosine and uridine than at guanosine and cytidine (pie charts). (c) RNP-MaP signal is minimally biased toward unstructured regions in Xist and XIST, as shown by the percentages (bar graphs) of RNP-MaP site nucleotides that also have low SHAPE reactivity (Lo-SHAPE), have low SHAPE reactivity and low modeled Shannon entropy (Lo-SS), or are base paired in minimum free-energy models (paired). (d) Positions of 151 high confidence eCLIP sites for 30 XIST-binding proteins used in this analysis are shown with RNP-MaP site density (top 5\% reactive sites per 51 nucleotides) aligned to the XIST sequence. Protein eCLIP sites are organized on density plots by identified community and ranked (from top to bottom) by decreasing summed mutual information of intra-community correlations.

Figure S9. PTBP1, MATR3, and TIA1 bind the XIST E region in vitro. (a) Correlation of $\log _{10}$ (mutation rates) of T7-transcribed XIST E region RNA with SDA and UV or UV alone in the absence of protein. MaP RT-induced mutation rates are identical (Pearson's $r=0.994)$. (b) $\log _{2}$ (reactivity) of RNP-MaP site nucleotides (red) as a function of indicated increasing protein concentration, compared to non-RNP-MaP nucleotides (black). Reactivities shown are averages for all nucleotides of each indicated nucleobase identity (right), and the number of nucleotides in each group present in each experiment is indicated. (c) Detection of RNP-MaP sites (represented as $25 \mathrm{nt}$ window densities) as a function of increasing amounts of PTBP1, MATR3, TIA1, and BSA (latter is control, no effect seen). Locations of eCLIP sites and class 1 and 2 motifs for each protein are indicated on density plots.

Figure S10. PTBP1, MATR3, and TIA1 networks observed in vitro do not fully recapitulate in-cell networks. (a) Recombinant PTBP1, MATR3, and TIA1 interact more strongly with motif class 2 than class 1 in XIST E region transcript in vitro, as shown by RNP-MaP reactivity, whereas motif class 1 is slightly more reactive in native XIST from HEK293 cells. (b) PTBP1 and TIA1 alone do not maintain significant interaction networks, as measured by mutual information (MI) density (summed over $25 \mathrm{nt}$ window), and MATR3 alone in vitro forms networks distinct from those observed in cells. (c) PTBP1, MATR3, and TIA1 eCLIP sites are only found within the uridine-rich region containing class 1 motifs but are absent in the uridine-poor region where RNPMaP identified class 2 motifs predominate. 
Table S1. Totals and summed mutual information (MI) of correlations linking pairwise combinations of XIST-binding protein eCLIP sites. P-values for both attributes were generated from 2000 randomizations (without replacement) of measured correlation locations along XIST (for nucleotides with sufficient read depth only). All measured correlations are included.

Table S2. Pairs of protein eCLIP sites significantly excluded (P-values $>0.95$ ) from RNPMaP data based on both total number of correlations and summed mutual information (MI) strength. Associated network communities, total numbers of each community pairing, and the percent of pairings that were significantly excluded are also listed.

Table S3. DNA sequences of MaP library preparation primers, plasmid construction, and qPCR primers. Sequences inserted during plasmid construction (bold and underlined) are shown with flanking plasmid sequences included (not bold or underlined).

Supplemental file 1. Structure-based sequence alignment of human RNase P and RMRP RNAs.

Supplemental file 2. List of high confidence eCLIP sites on XIST organized by protein. 
bioRxiv preprint doi: https://doi.org/10.1101/2020.02.07.939108; this version posted February 9, 2020. The copyright holder for this preprint (which was not certified by peer review) is the author/funder. All rights reserved. No reuse allowed without permission.

Figure 1

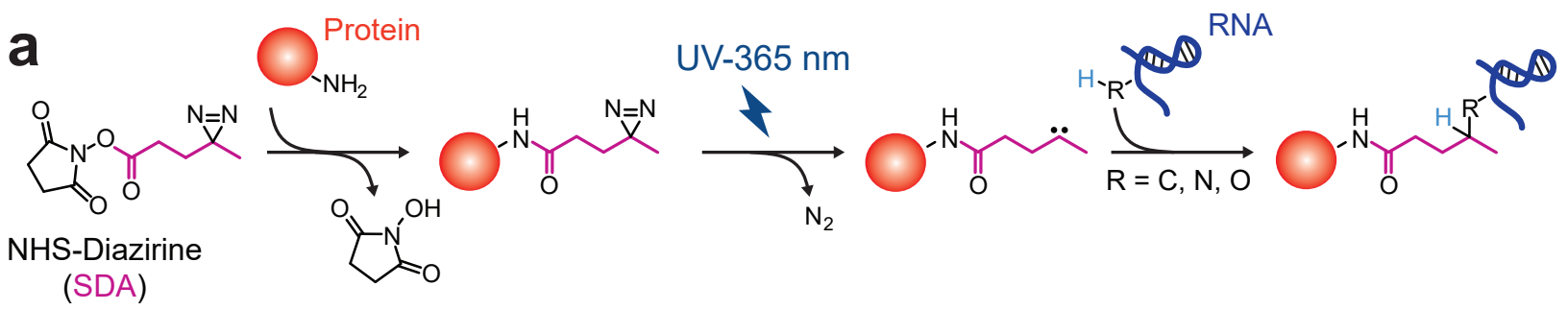

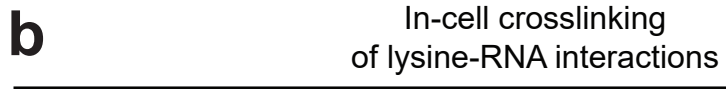

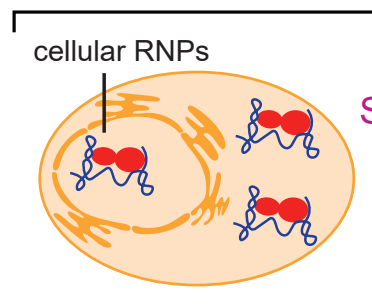

Mutations mark protein-binding sites

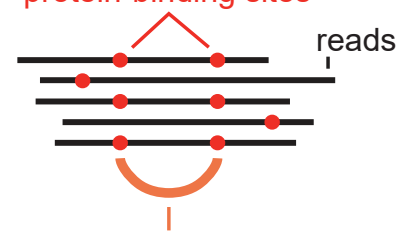

Correlations identify

interaction networks
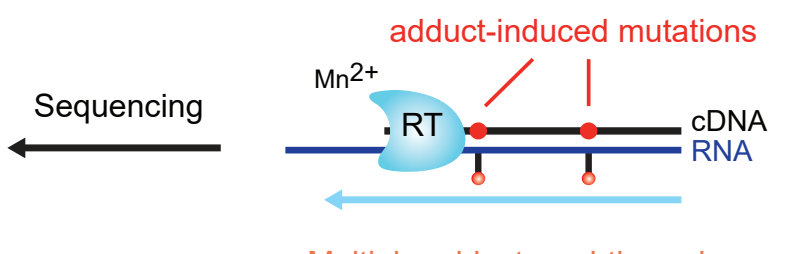

Multiple adduct read-through on individual RNA molecules

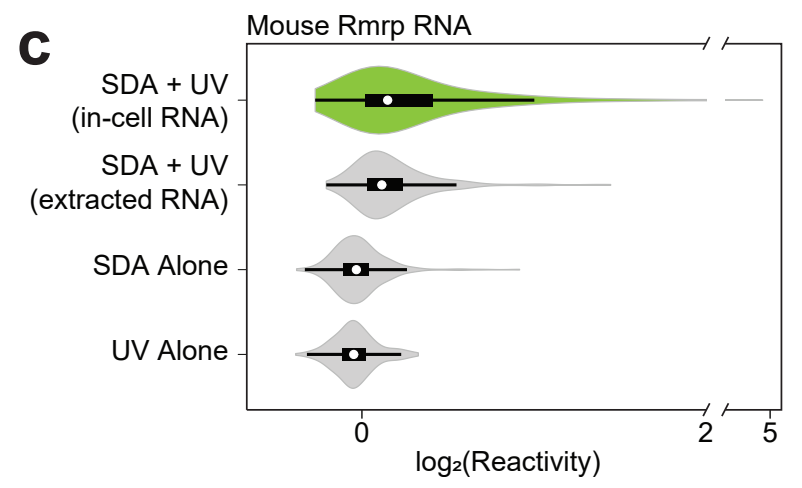

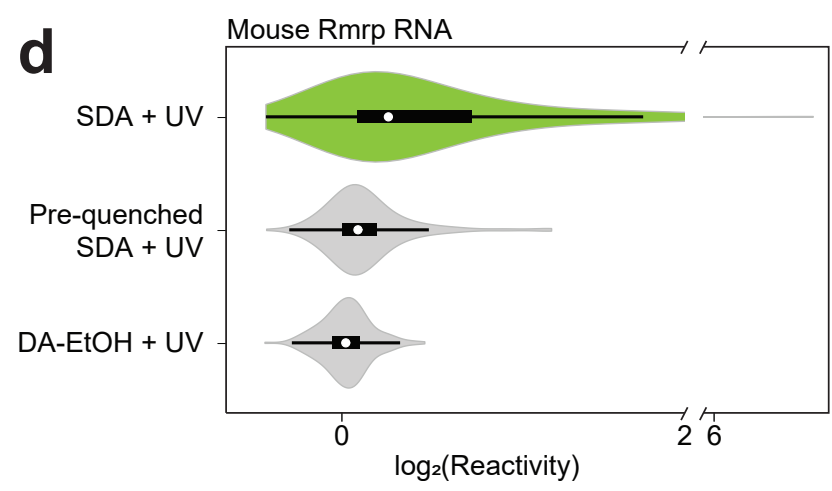

RNA with peptide adducts

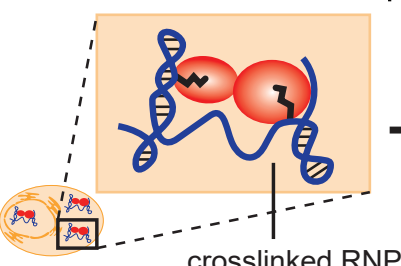

crosslinked RNP digestion

.

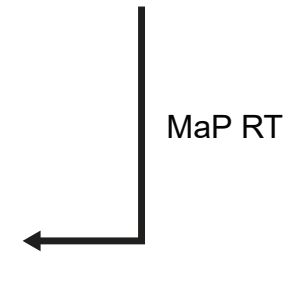

$g_{2}$ (Reactivity) 
Figure 2

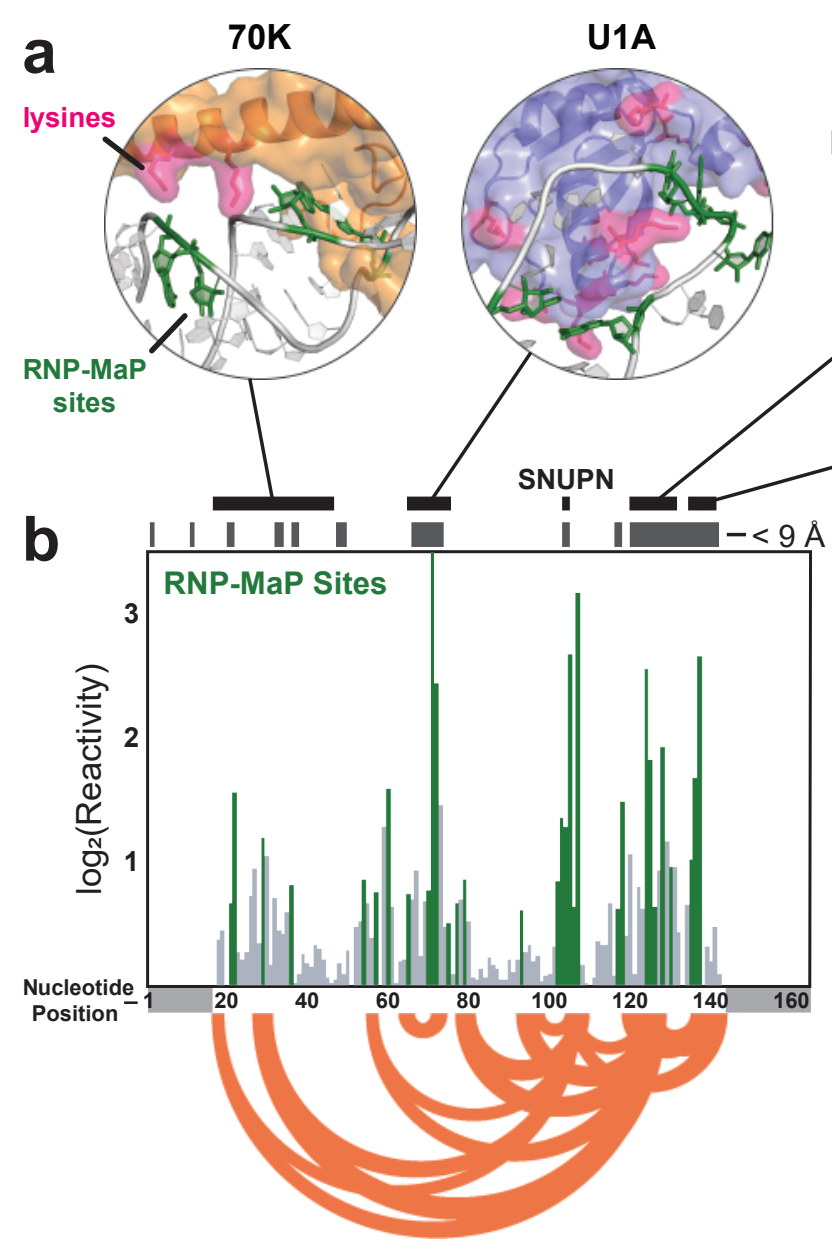

RNP-MaP Correlations
Sm Complex

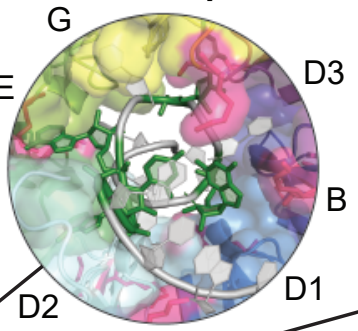

$\mathrm{D} 2$

from lysine amine
C

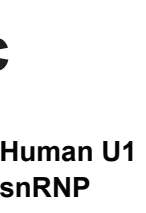

Sm Complex - 70K

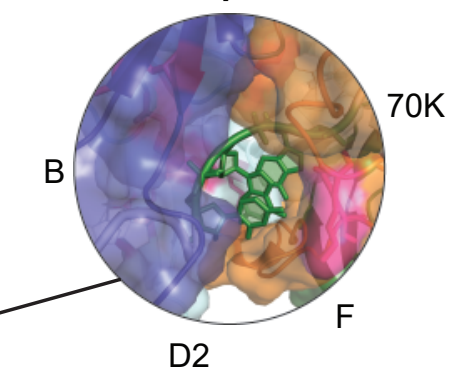

- RNP-MaP site

$\bigcirc$ - primer sequence
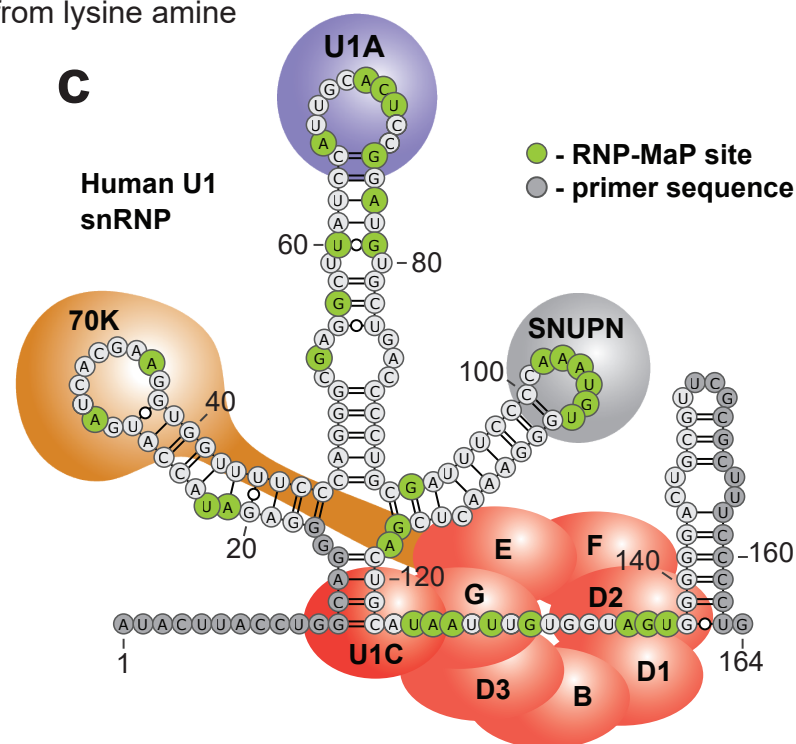

Sm Complex 
bioRxiv preprint doi: https://doi.org/10.1101/2020.02.07.939108; this version posted February 9, 2020. The copyright holder for this preprint (which was not certified by peer review) is the author/funder. All rights reserved. No reuse allowed without permission.

Figure 3

a

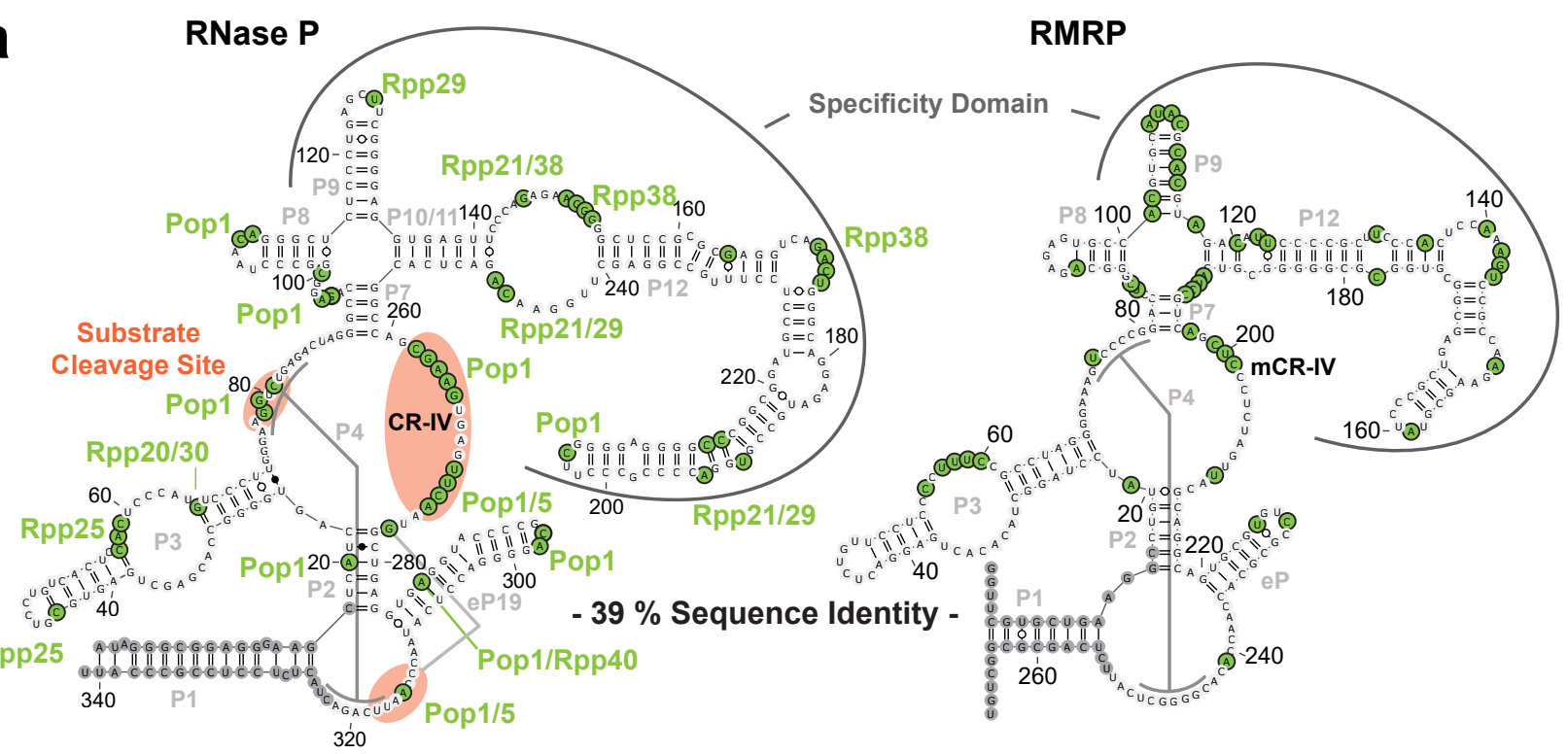

b

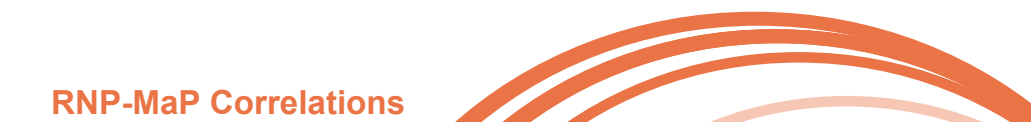

RNase P

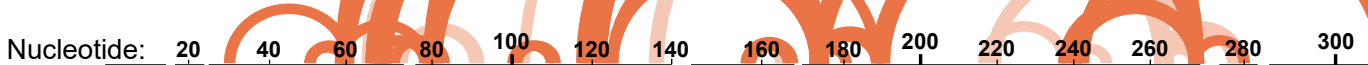

Conserved

(P\#)

RNP-MaP Correlations
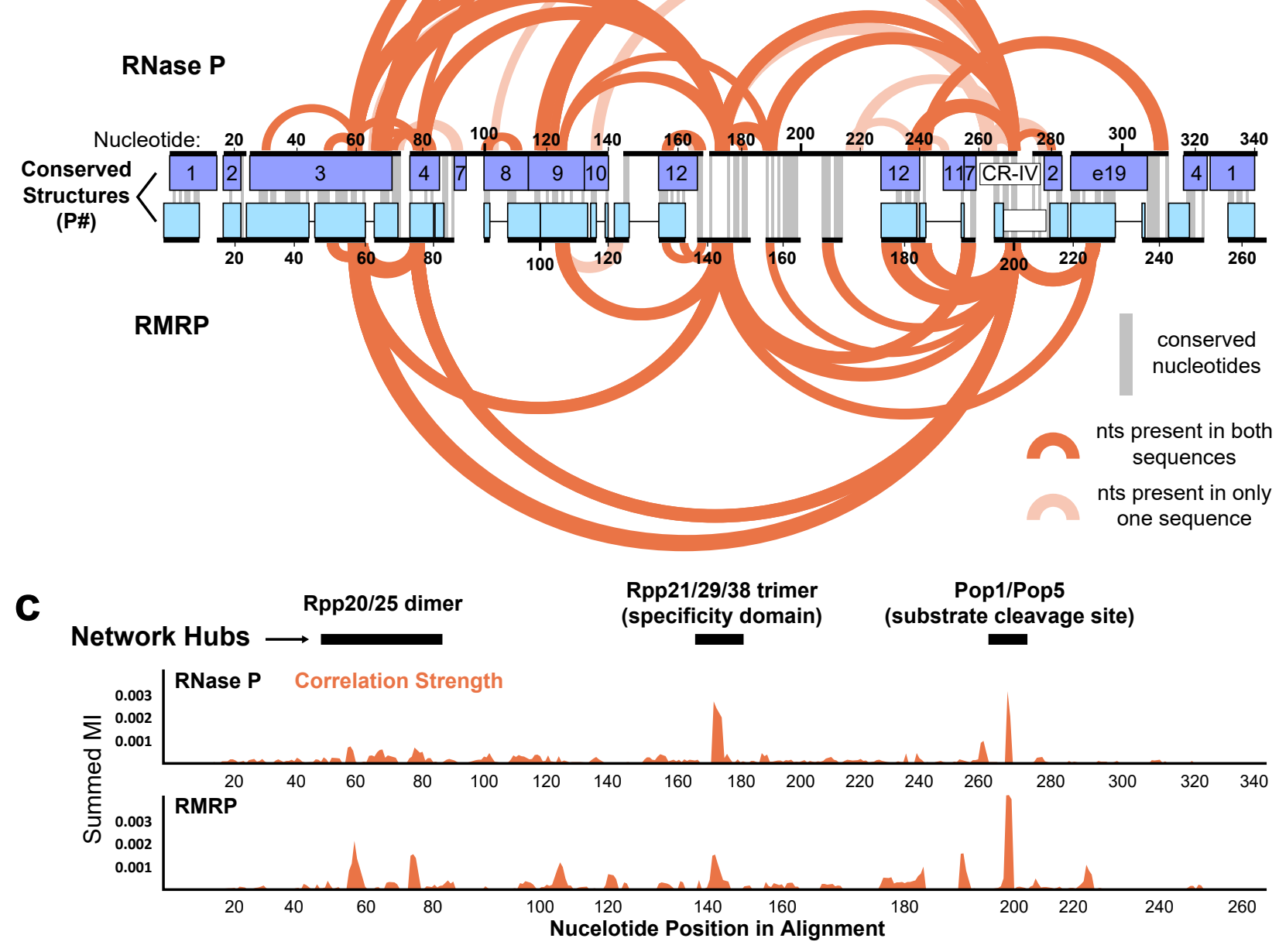
bioRxiv preprint doi: https://doi.org/10.1101/2020.02.07.939108; this version posted February 9, 2020. The copyright holder for this preprint (which was not certified by peer review) is the author/funder. All rights reserved. No reuse allowed without permission.

Figure 4
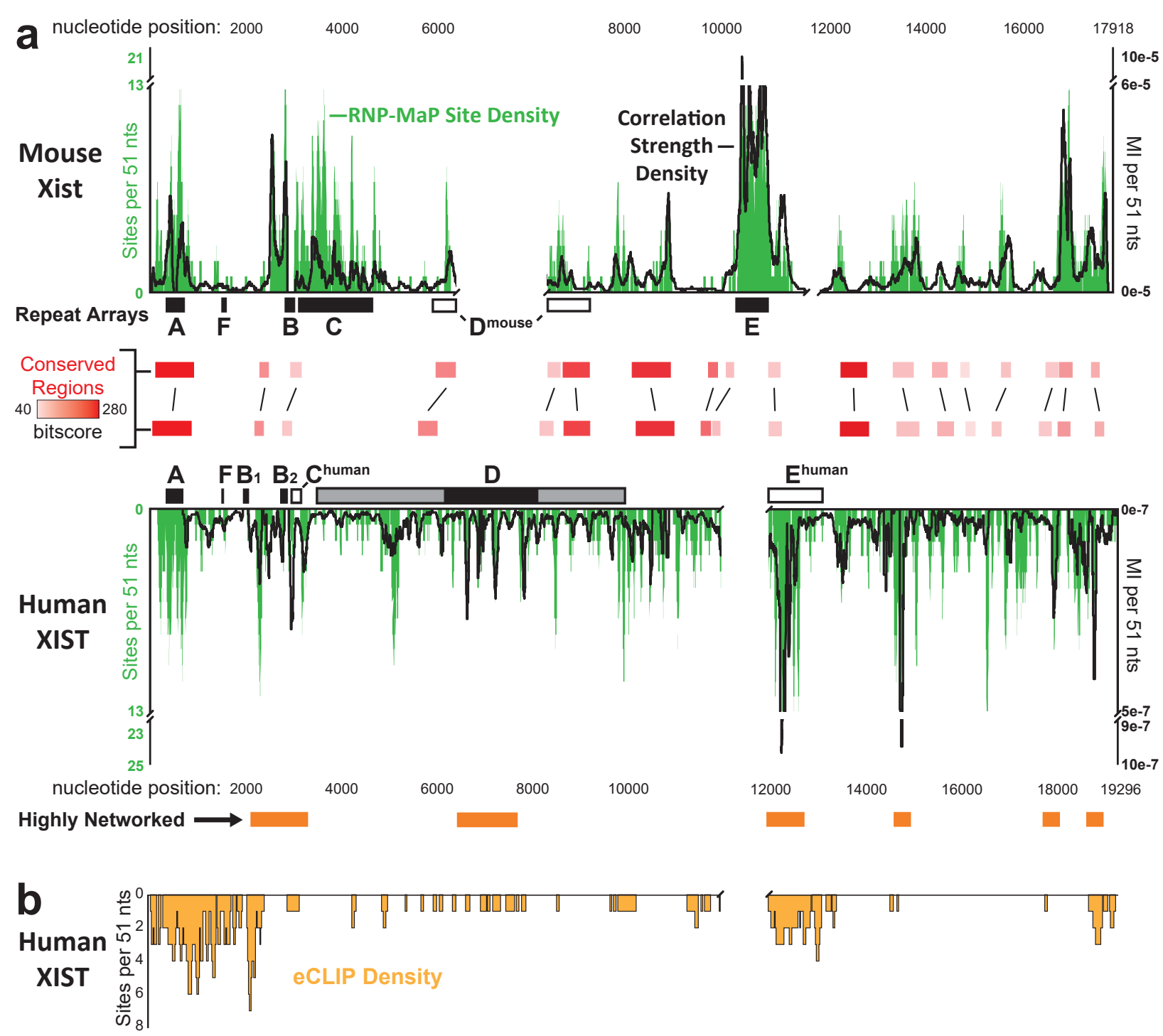
bioRxiv preprint doi: https://doi.org/10.1101/2020.02.07.939108; this version posted February 9, 2020. The copyright holder for this preprint (which was not certified by peer review) is the author/funder. All rights reserved. No reuse allowed without permission.

Figure 5

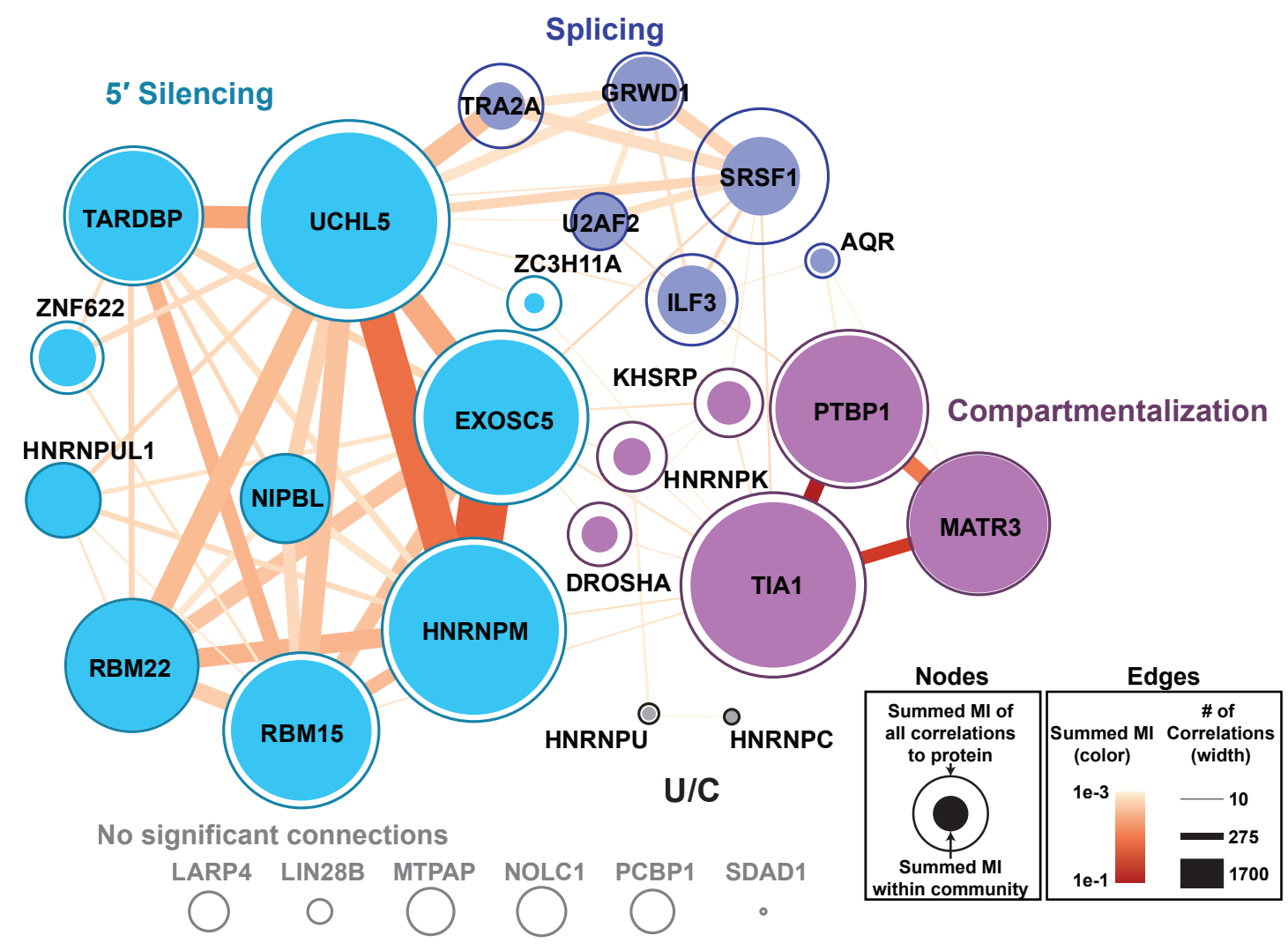


bioRxiv preprint doi: https://doi.org/10.1101/2020.02.07.939108; this version posted February 9, 2020. The copyright holder for this preprint (which was not certified by peer review) is the author/funder. All rights reserved. No reuse allowed without permission.

Figure 6
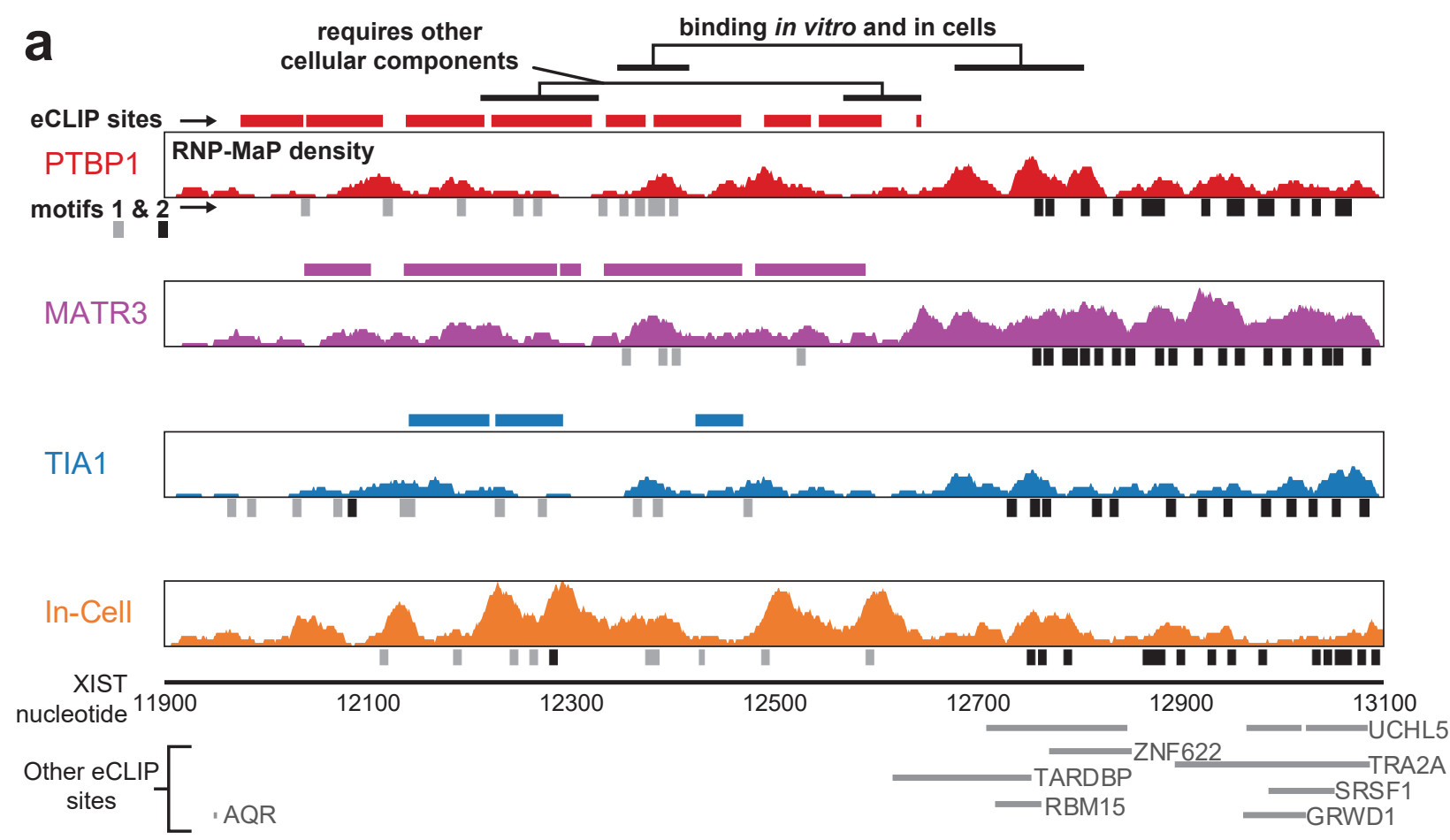

b

motif class $1^{*}$

(Not Significant)

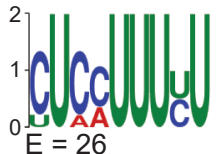

$\underbrace{2}_{E=170}$

$\stackrel{\infty}{m}$
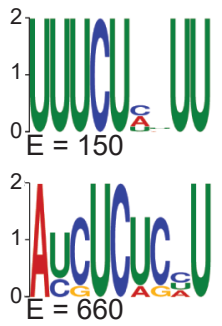

d motif class 2

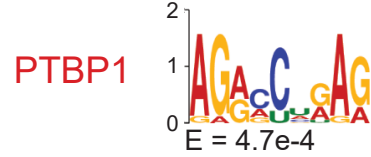

MATR3 ${ }^{2} .\left.\right|_{0} ^{2}=9.9 \mathrm{e}-8$

TIA1

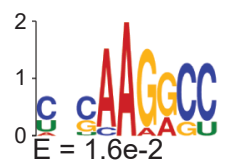

2

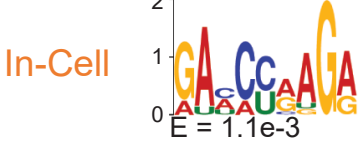

Non-XIST insert
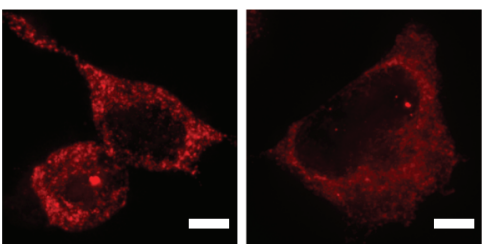

Nuclei

(DAPI)

Reporter

(ISH)
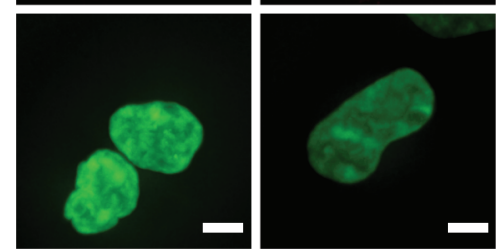

C

reporter RNA levels

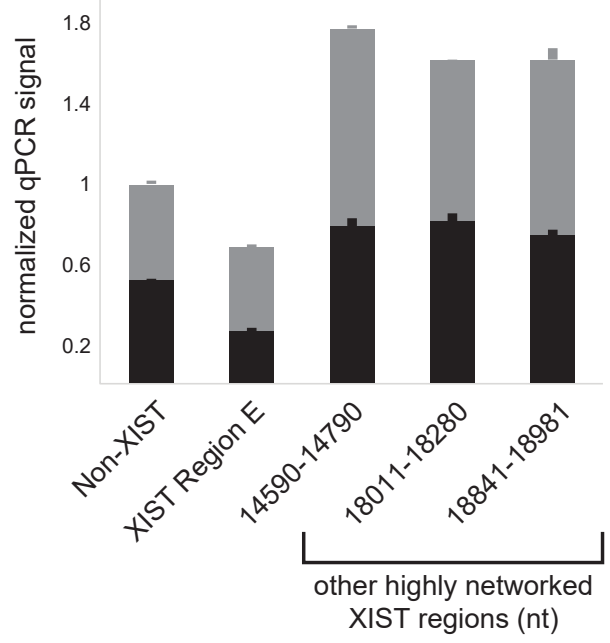

Nucleus

Cytoplasm 
bioRxiv preprint doi: https://doi.org/10.1101/2020.02.07.939108; this version posted February 9, 2020. The copyright holder for this preprint (which was not certified by peer review) is the author/funder. All rights reserved. No reuse allowed without permission.

Figure S1
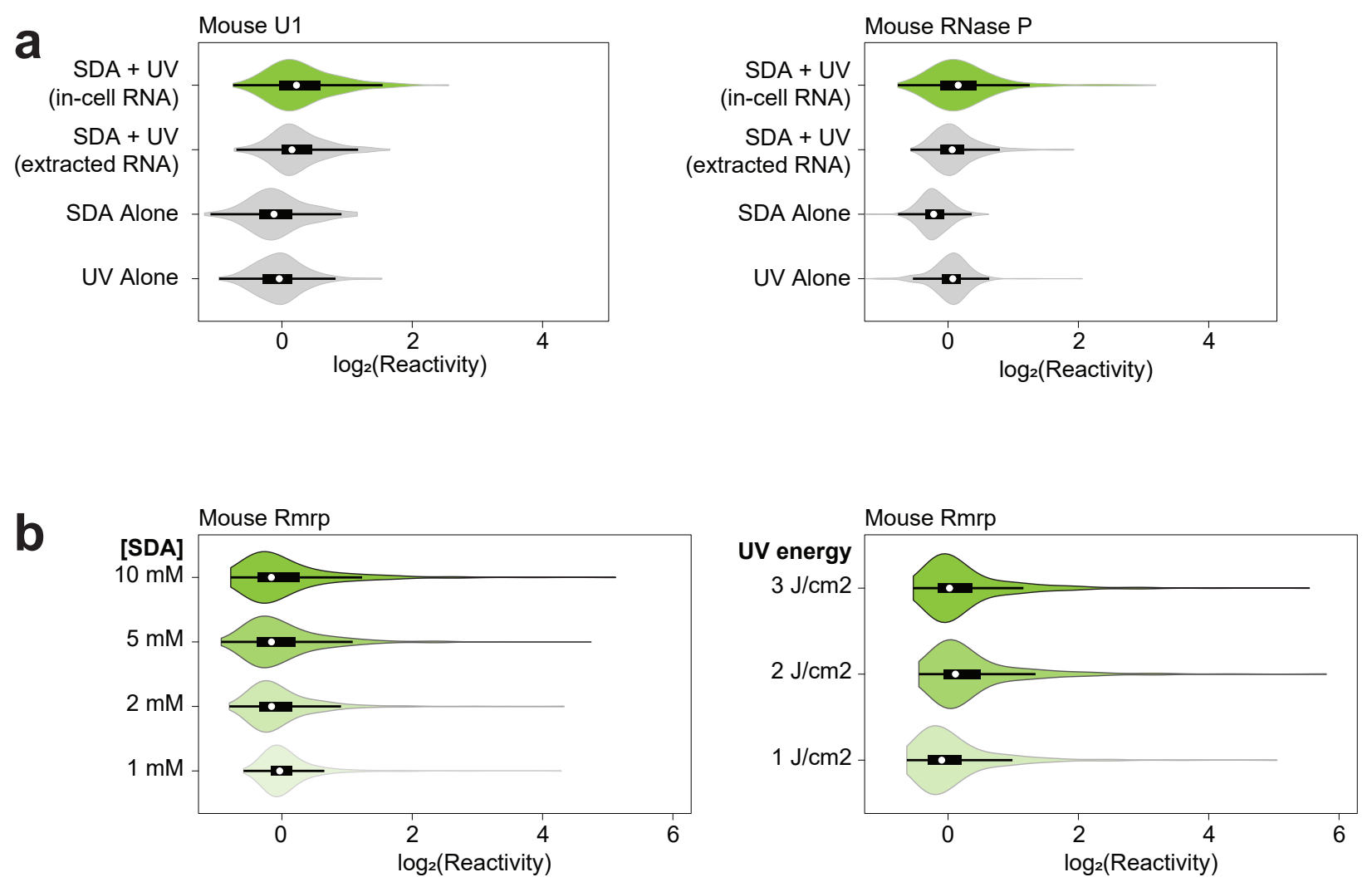
a RNP-MaP site calling

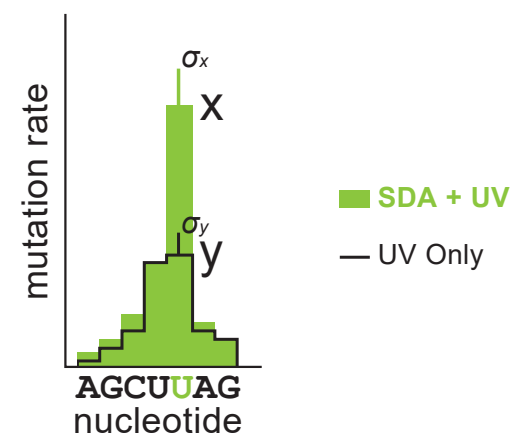

For nucleotides (nt)

with $\mathrm{x}$ and $\mathrm{y}$ depths $>5000$ :

$$
\begin{gathered}
\sigma_{n t}=\frac{\sqrt{\text { mutation rate } n t}}{\sqrt{\text { reads } n t}} \\
\text { Z-factor: } \\
1-\frac{2.575\left(\sigma_{\mathrm{x}}+\sigma_{\mathrm{y}}\right)}{|\mathrm{x}-\mathrm{y}|} \\
\text { Diff } \mathrm{nt}_{\mathrm{n}}=\mathrm{x}_{\mathrm{nt}} / \mathrm{ynt}
\end{gathered}
$$

Nucleotide-specific thresholds (NTthresh):

For U: Medianu-Diffs $+0.59 *$ SDu-Diffs For A: MedianA-Diffs $+0.29 * \mathrm{SD}_{\text {A-Diffs }}$ For C: Medianc-Diffs $+0.93^{*} \mathrm{SD}_{\mathrm{C} \text {-Diffs }}$ For G: MedianG-Diffs $+0.78 * \mathrm{SD}_{\mathrm{G}-\mathrm{Diffs}}$ $S D_{\text {Diffs }}=\sqrt{\frac{1}{N} \sum_{i=1}^{N}\left(D_{N T=U, A, c, \text { or } G} \text { iff }_{N T}-\overline{\operatorname{DiffS}}_{N T}\right)^{2}}$ RNP-MaP sites are where: the \# of mutations observed above background $\geq 50$

Z-factor $>0$

Diff $_{n t}>$ NTthresh

\section{b RNP-MaP correlation calling}

RNA -

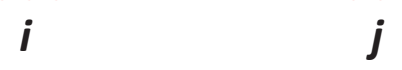

For all 3-nt windows $\mathrm{i}$ and $\mathrm{j}$ that are:

- separated by $>4 \mathrm{nts}$

- are included in $\geq 10,000$ reads

- have $\mathrm{i}$ and $\mathrm{j}$ background mutation rates $<6 \%$

If counts:

\begin{tabular}{l|c|c|c}
\multicolumn{1}{c}{$i_{\text {not }}$} & \multicolumn{3}{c}{ margin 1 } \\
\cline { 2 - 4 }$j_{\text {not }}$ & $A$ & $B$ & $A+B$ \\
\cline { 2 - 4 }$j_{\text {mut }}$ & $C$ & $D$ & $C+D$ \\
\cline { 2 - 4 } & $A+C$ & $B+D$ & $N_{\text {total }}$
\end{tabular}

mutual information (MI) is:

$$
\frac{N_{\text {total }} \cdot \ln \left(N_{\text {total }}\right)+\left(\sum_{n=A, B, C, D} n \cdot \ln (n)\right)-\left(\sum_{m=A+B, C+D, A+C, B+D} m \cdot \ln (m)\right)}{N_{\text {total }}}
$$

and then:

$$
\text { G-statistic }=2 \cdot \mathrm{N}_{\text {total }} \cdot \mathrm{MI}
$$

observed correlations are kept if:

- co-mutations observed $>50$ times

- achieve G-statistic $\geq 20\left(P<10^{-5}\right)$

- G-statistic in background $<10.83(P<0.001)$

RNP-MaP correlations

plotted as arcs connecting nucleotide triplet pairs

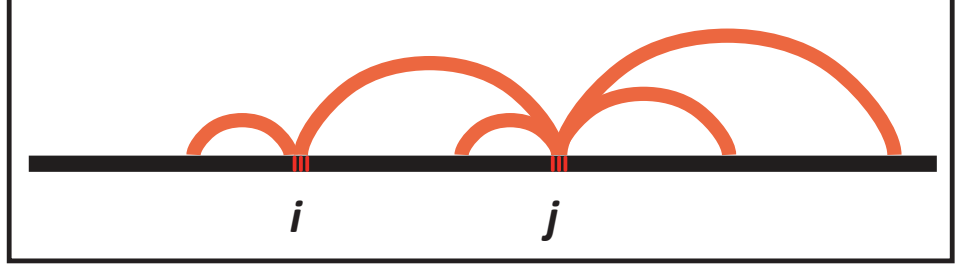


bioRxiv preprint doi: https://doi.org/10.1101/2020.02.07.939108; this version posted February 9, 2020. The copyright holder for this preprint (which was not certified by peer review) is the author/funder. All rights reserved. No reuse allowed without permission.

Figure S3
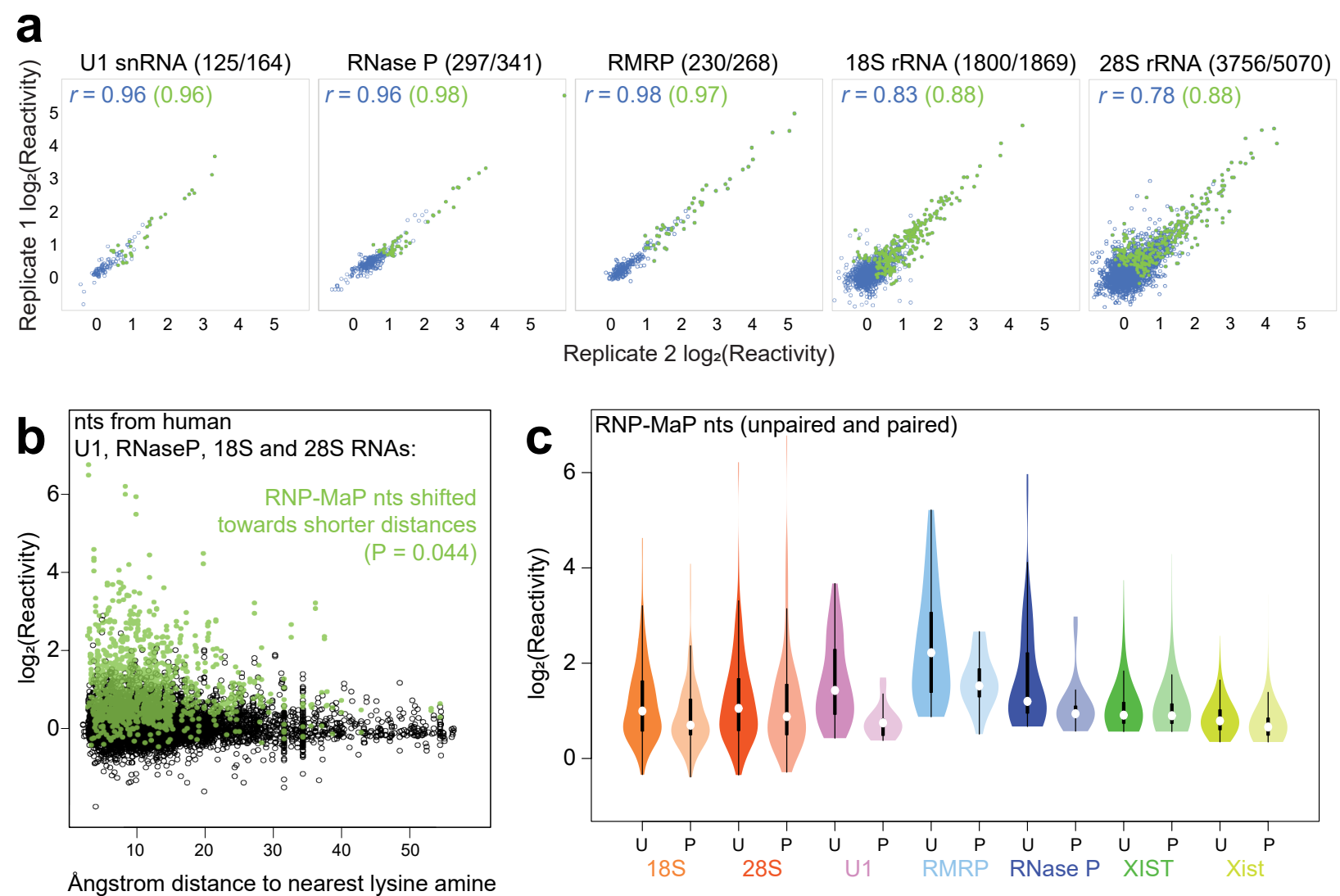

Ångstrom distance to nearest lysine amine
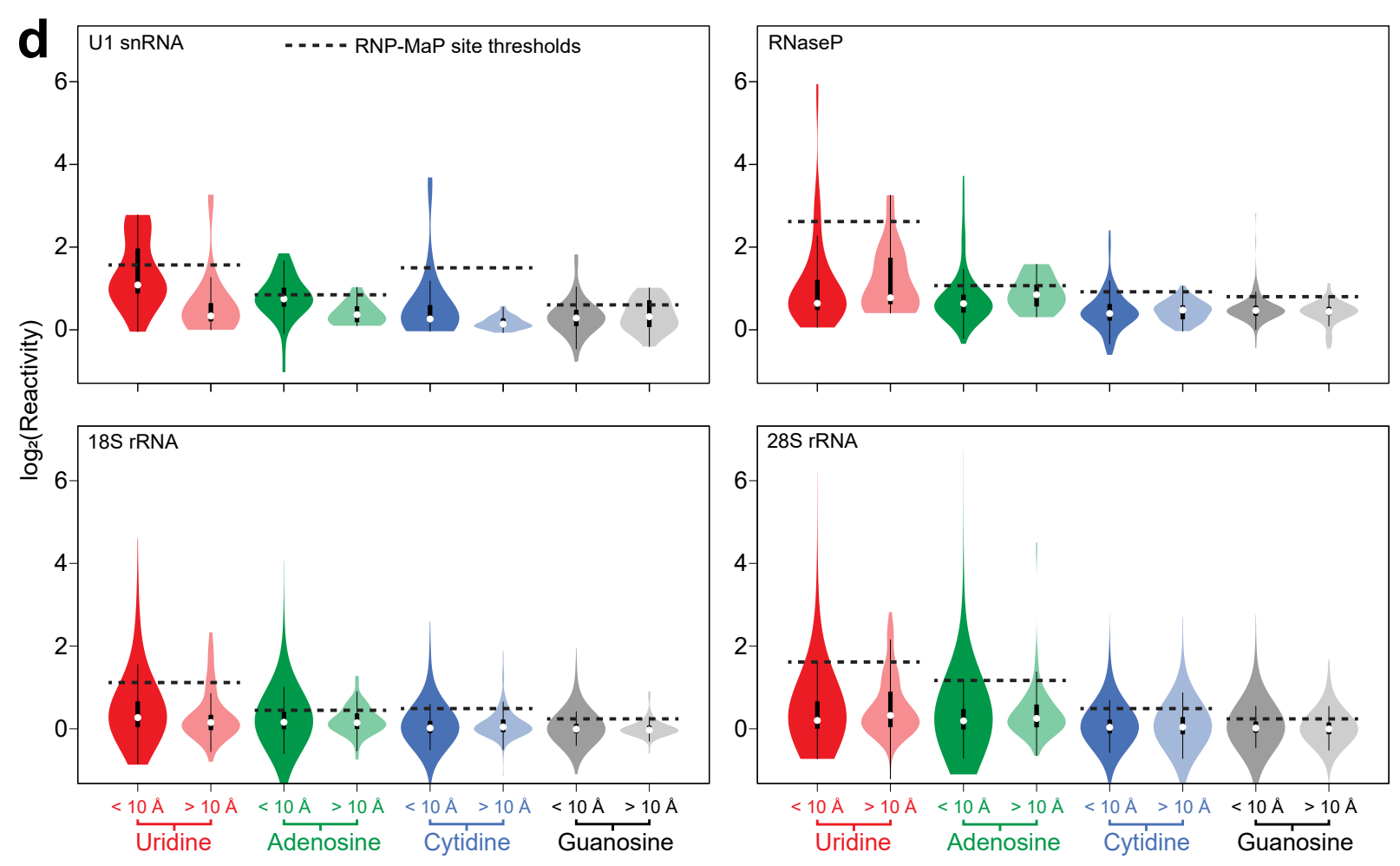
bioRxiv preprint doi: https://doi.org/10.1101/2020.02.07.939108; this version posted February 9, 2020. The copyright holder for this preprint (which was not certified by peer review) is the author/funder. All rights reserved. No reuse allowed without permission.

Figure S4

\section{a RNP-MaP vs. $\triangle$ SHAPE}
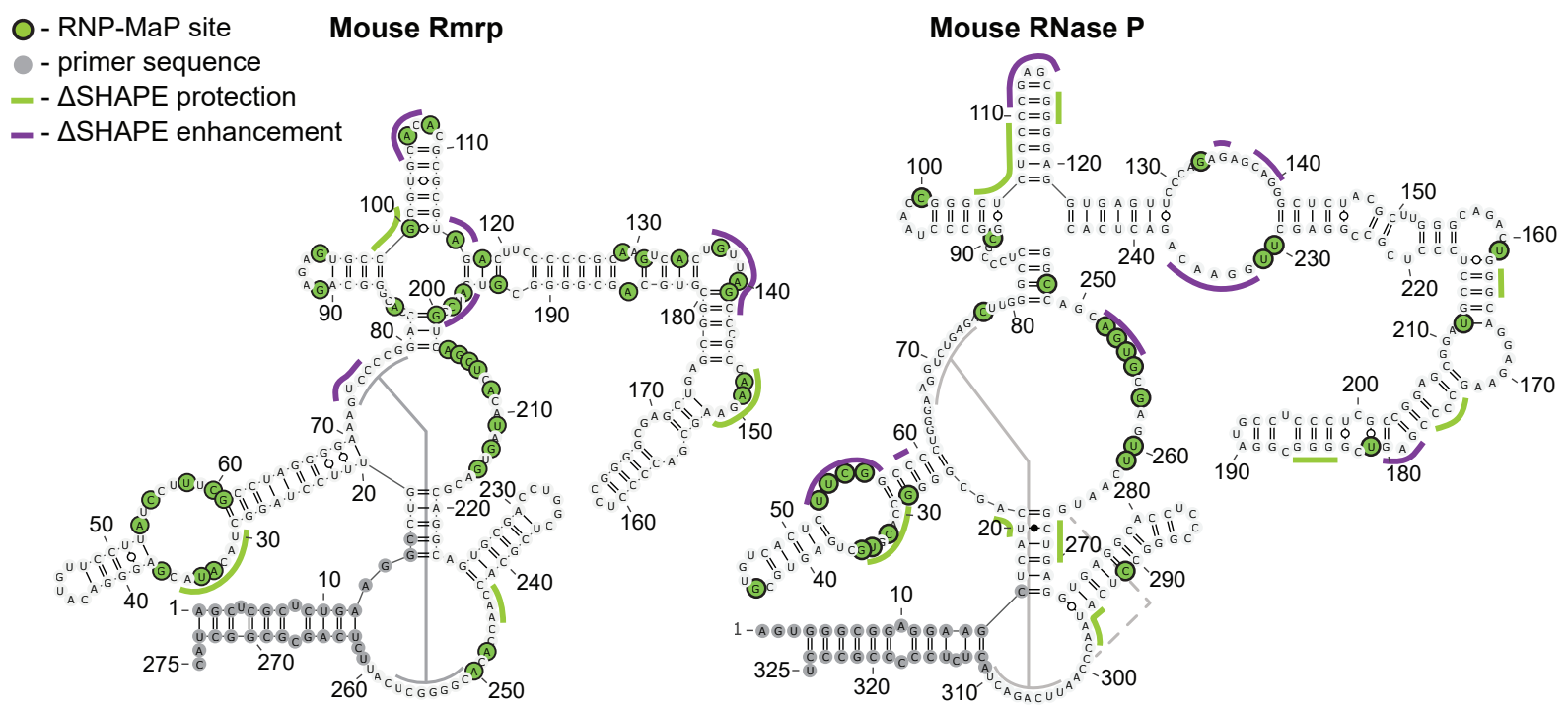

\section{b RNP-MaP vs. photo-lysine}
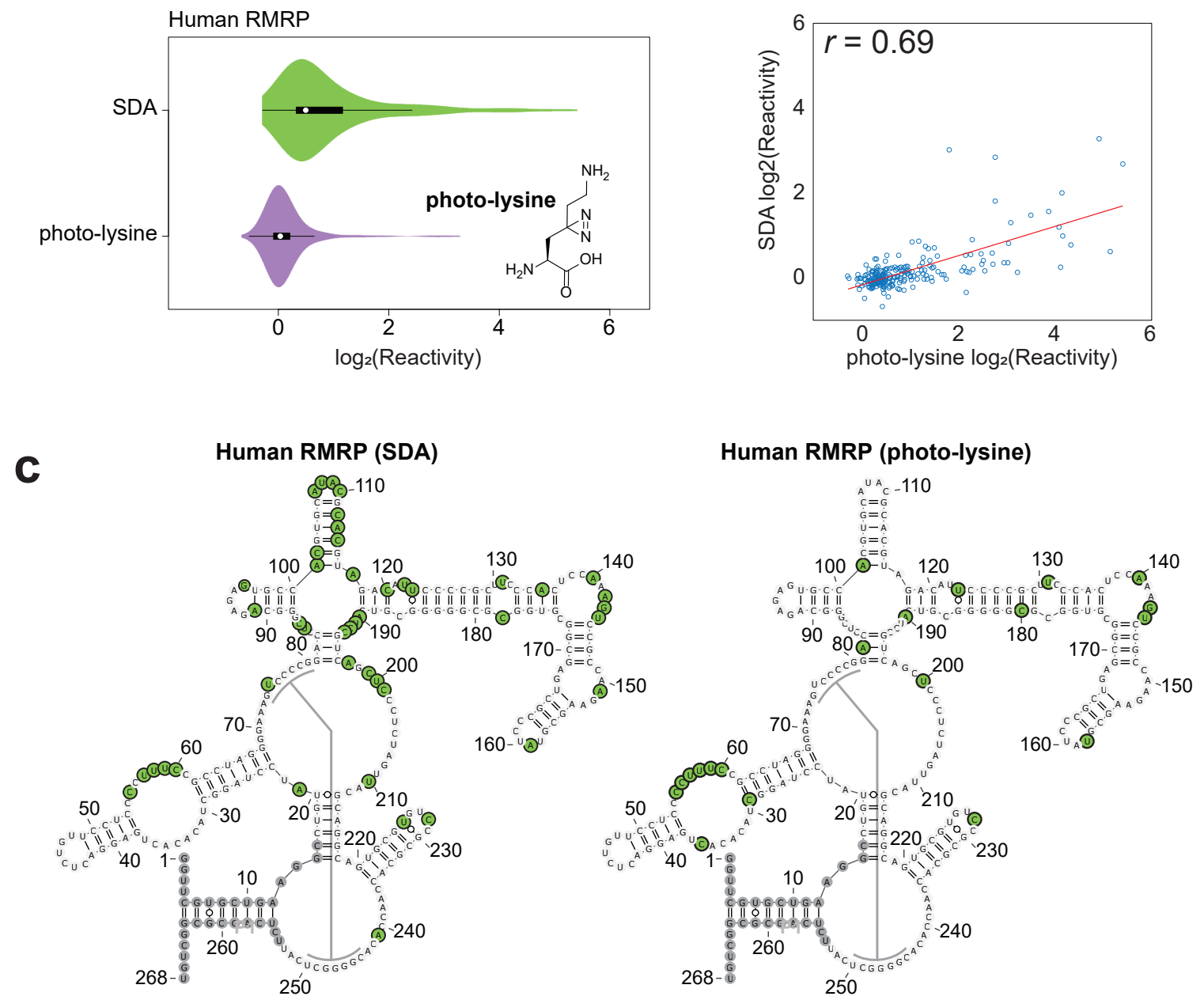
bioRxiv preprint doi: https://doi.org/10.1101/2020.02.07.939108; this version posted February 9, 2020. The copyright holder for this preprint (which was not certified by peer review) is the author/funder. All rights reserved. No reuse allowed without permission.

Figure S5
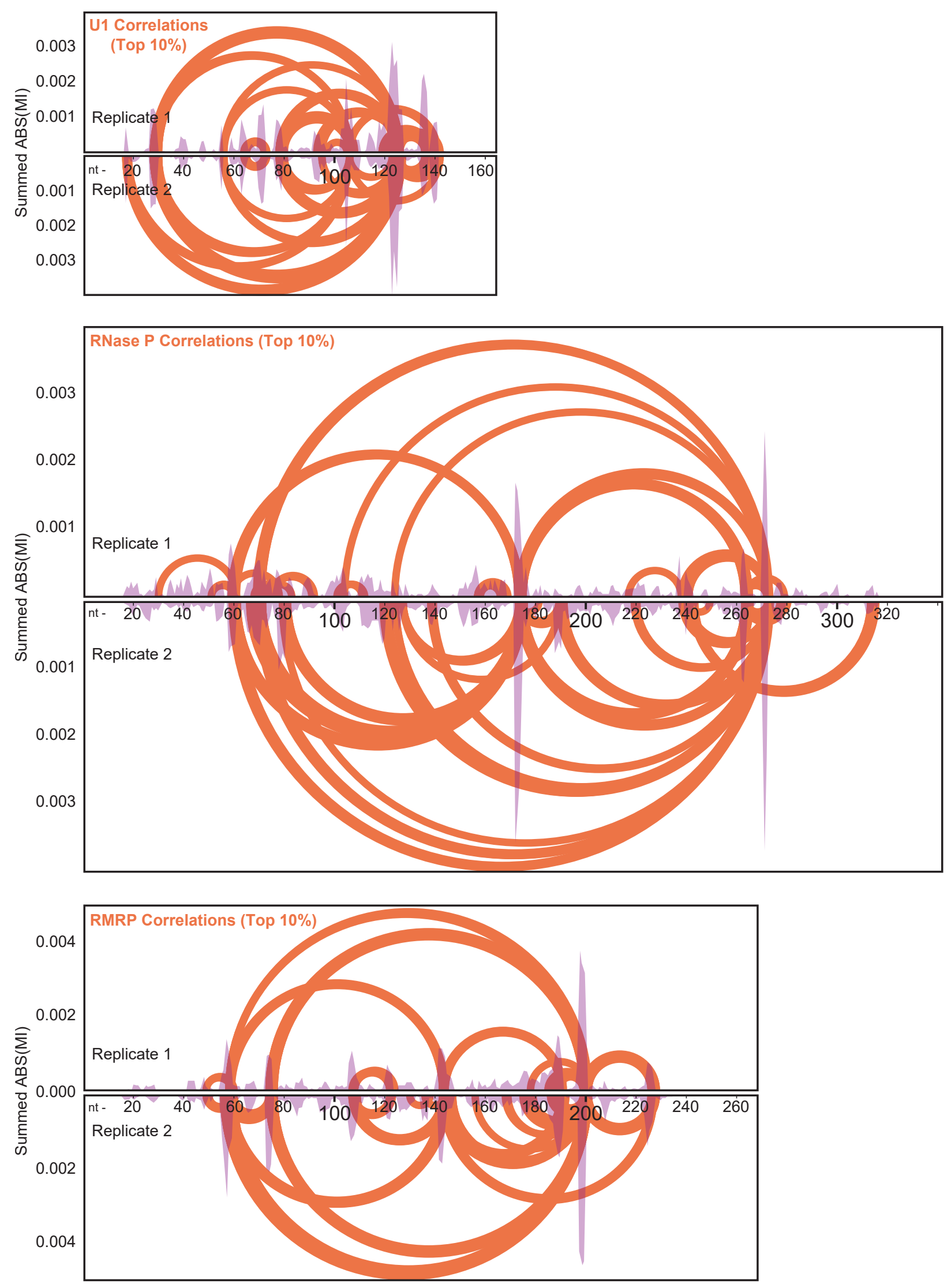
bioRxiv preprint doi: https://doi.org/10.1101/2020.02.07.939108; this version posted February 9, 2020. The copyright holder for this preprint (which was not certified by peer review) is the author/funder. All rights reserved. No reuse allowed without permission.

Figure S6

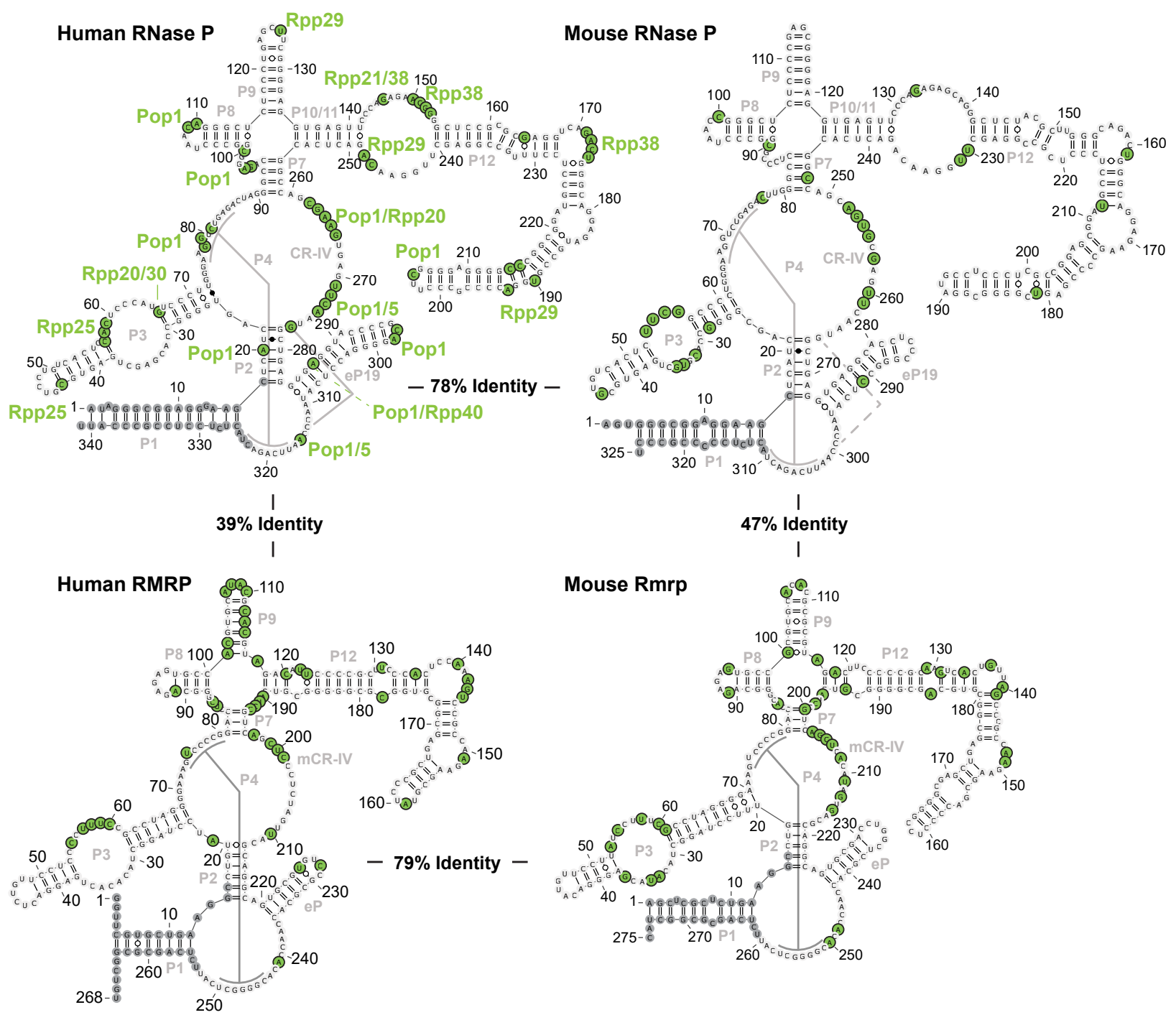


bioRxiv preprint doi: https://doi.org/10.1101/2020.02.07.939108; this version posted February 9, 2020. The copyright holder for this preprint (which was not certified by peer review) is the author/funder. All rights reserved. No reuse allowed without permission.

Figure S7

a

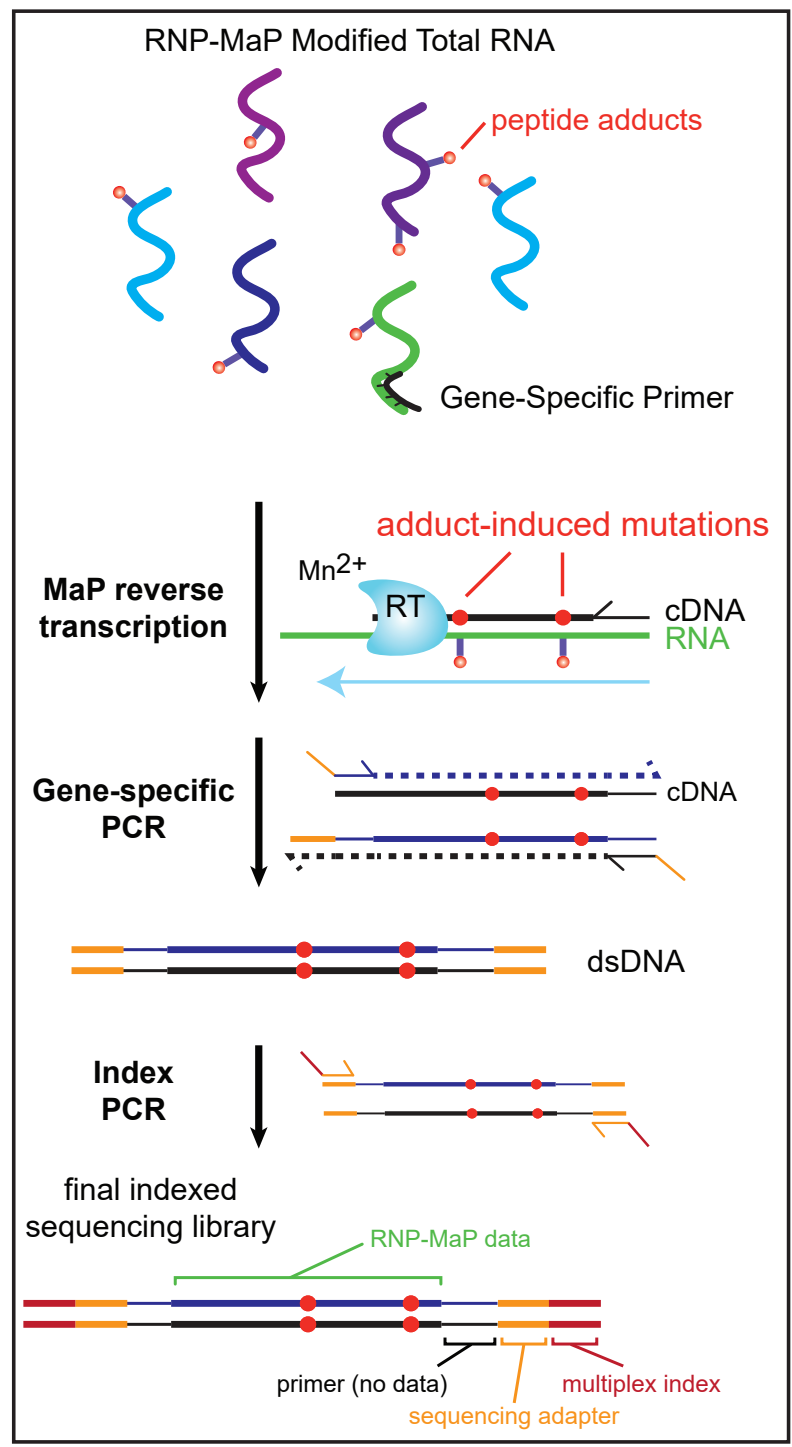

b

RNA antisense pull-down and random priming for long RNAs

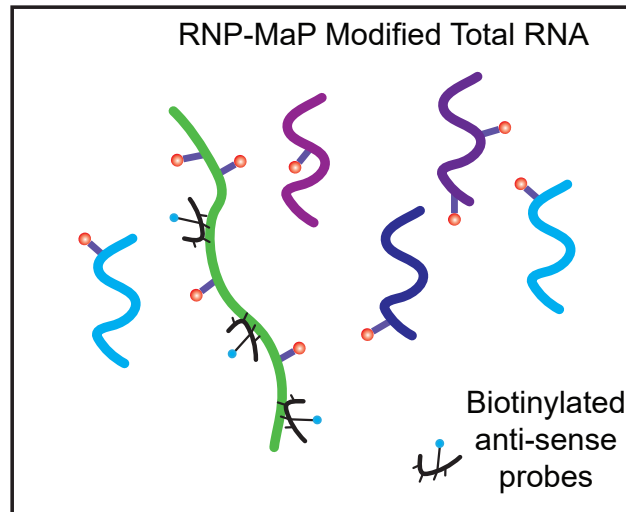

RNA antisense pull-down

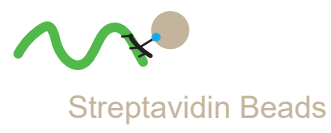

Enriched Modified long RNA
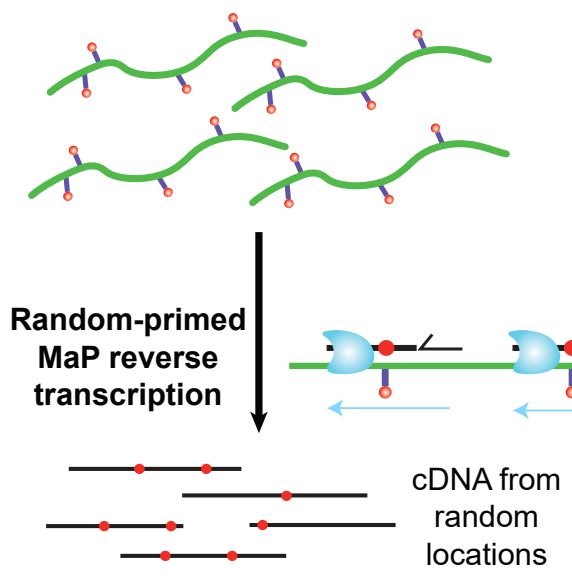

Second strand synthesis

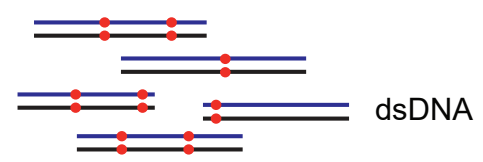

Combined fragmentation, indexing, and amplification

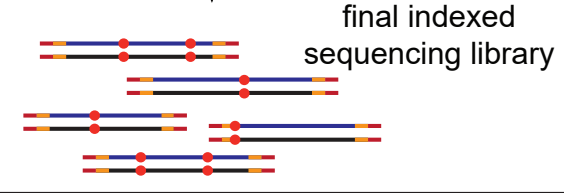


bioRxiv preprint doi: https://doi.org/10.1101/2020.02.07.939108; this version posted February 9, 2020. The copyright holder for this preprint (which was not certified by peer review) is the author/funder. All rights reserved. No reuse allowed without permission.

Figure S8

Mouse Xist
NT: 1

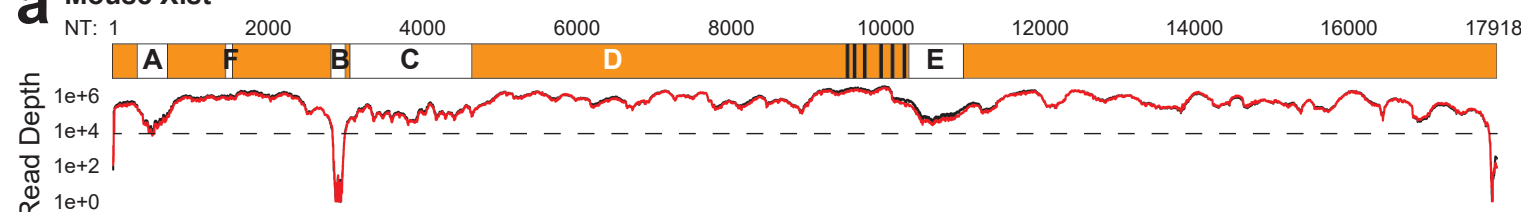

$\stackrel{\circledast}{\simeq} 1 \mathrm{e}+0$

Human XIST

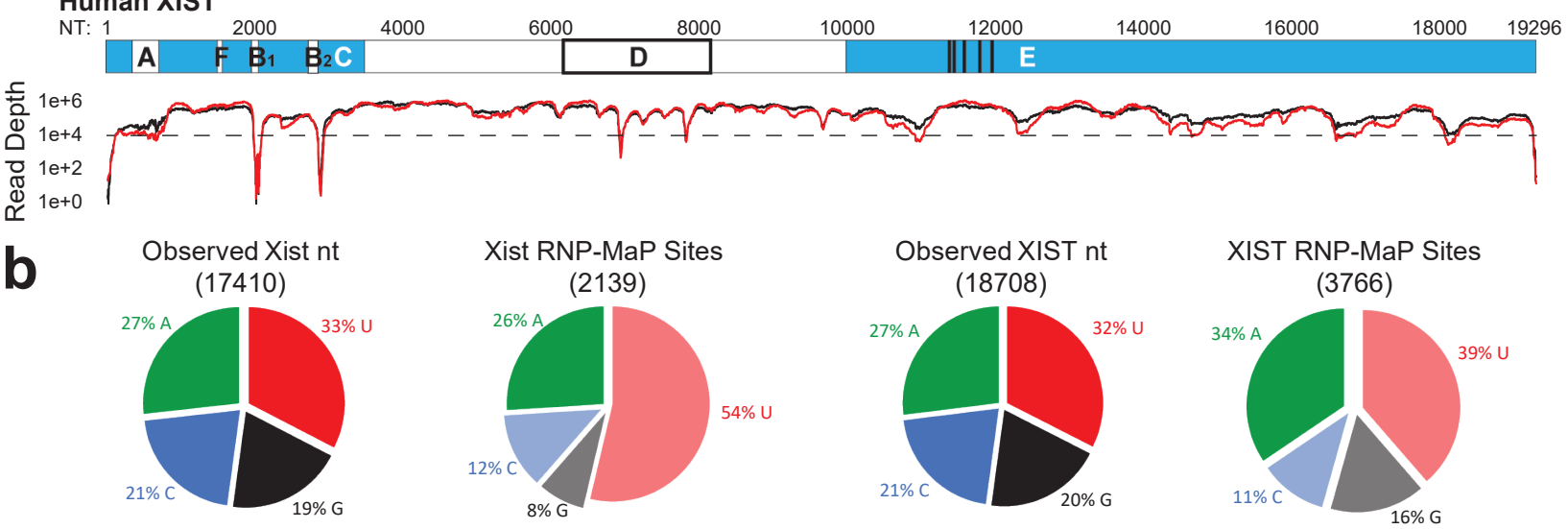

C

Mouse Xist

Human XIST
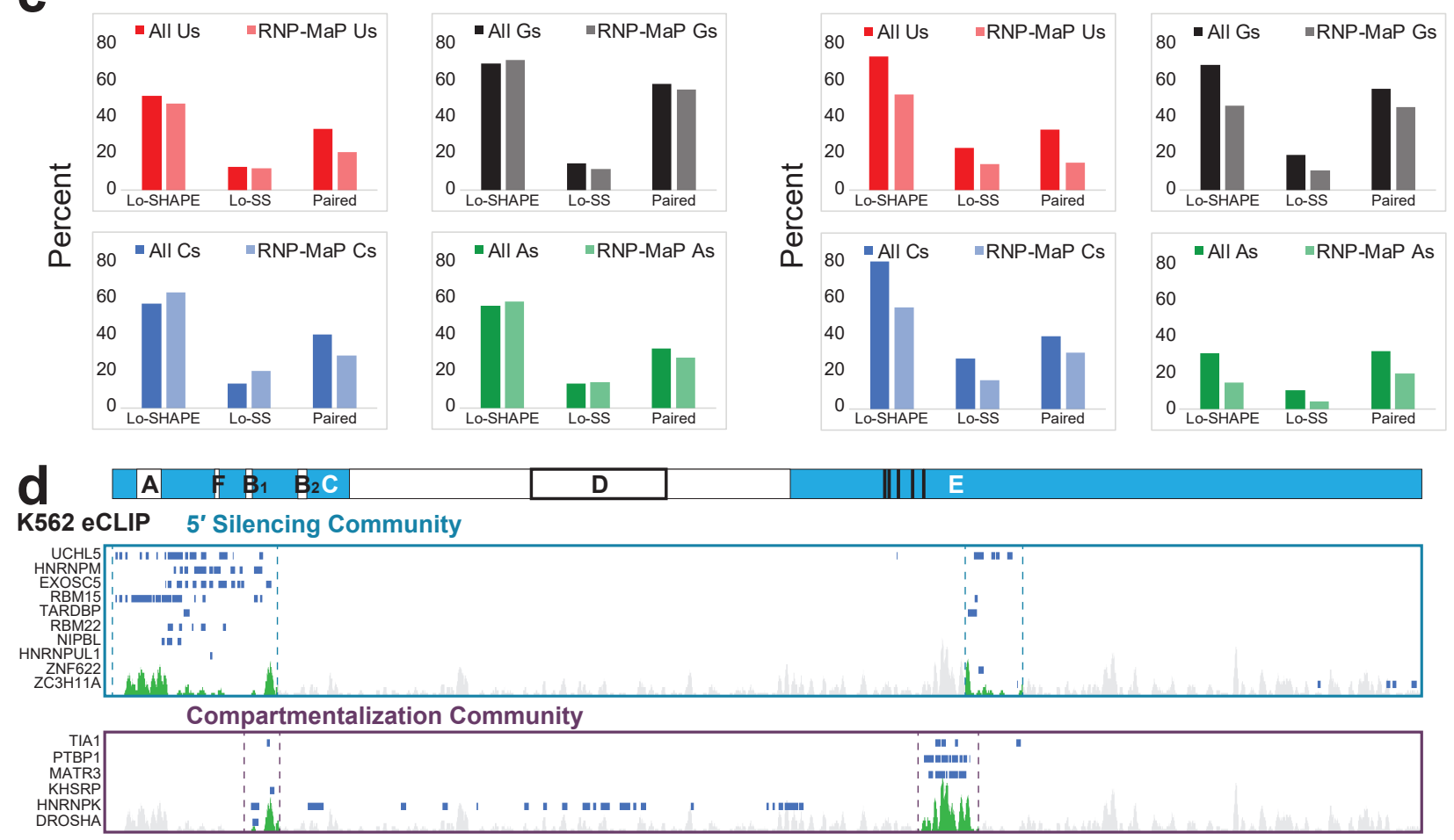

Splicing Community

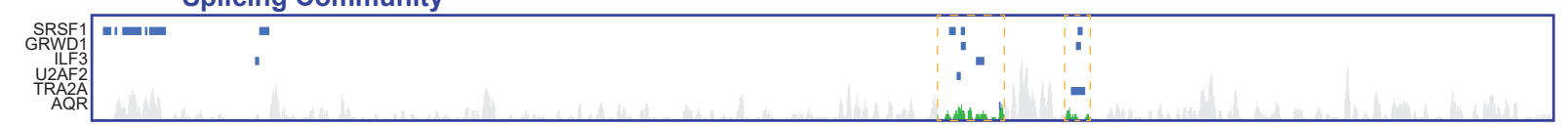

\begin{tabular}{l} 
U/C Community \\
\cline { 2 - 4 }
\end{tabular}


bioRxiv preprint doi: https://doi.org/10.1101/2020.02.07.939108; this version posted February 9, 2020. The copyright holder for this preprint (which was not certified by peer review) is the author/funder. All rights reserved. No reuse allowed without permission.

Figure S9
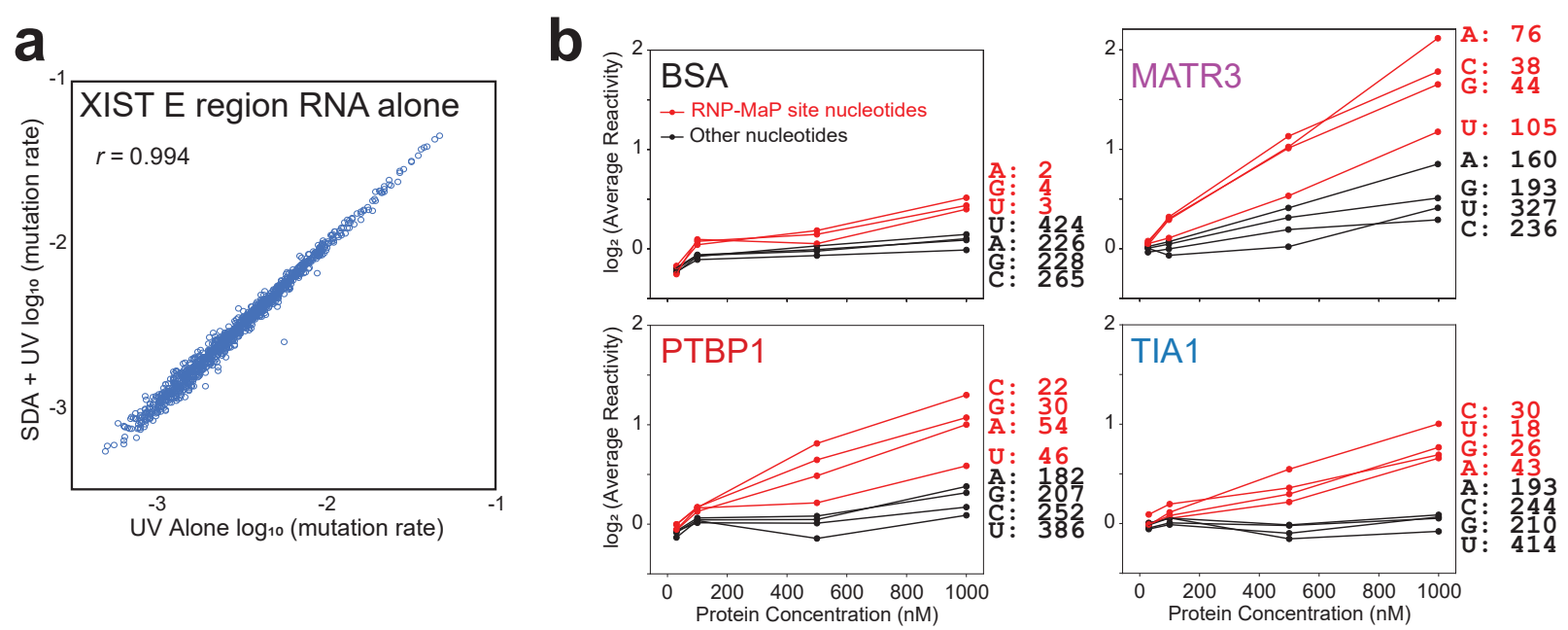

C
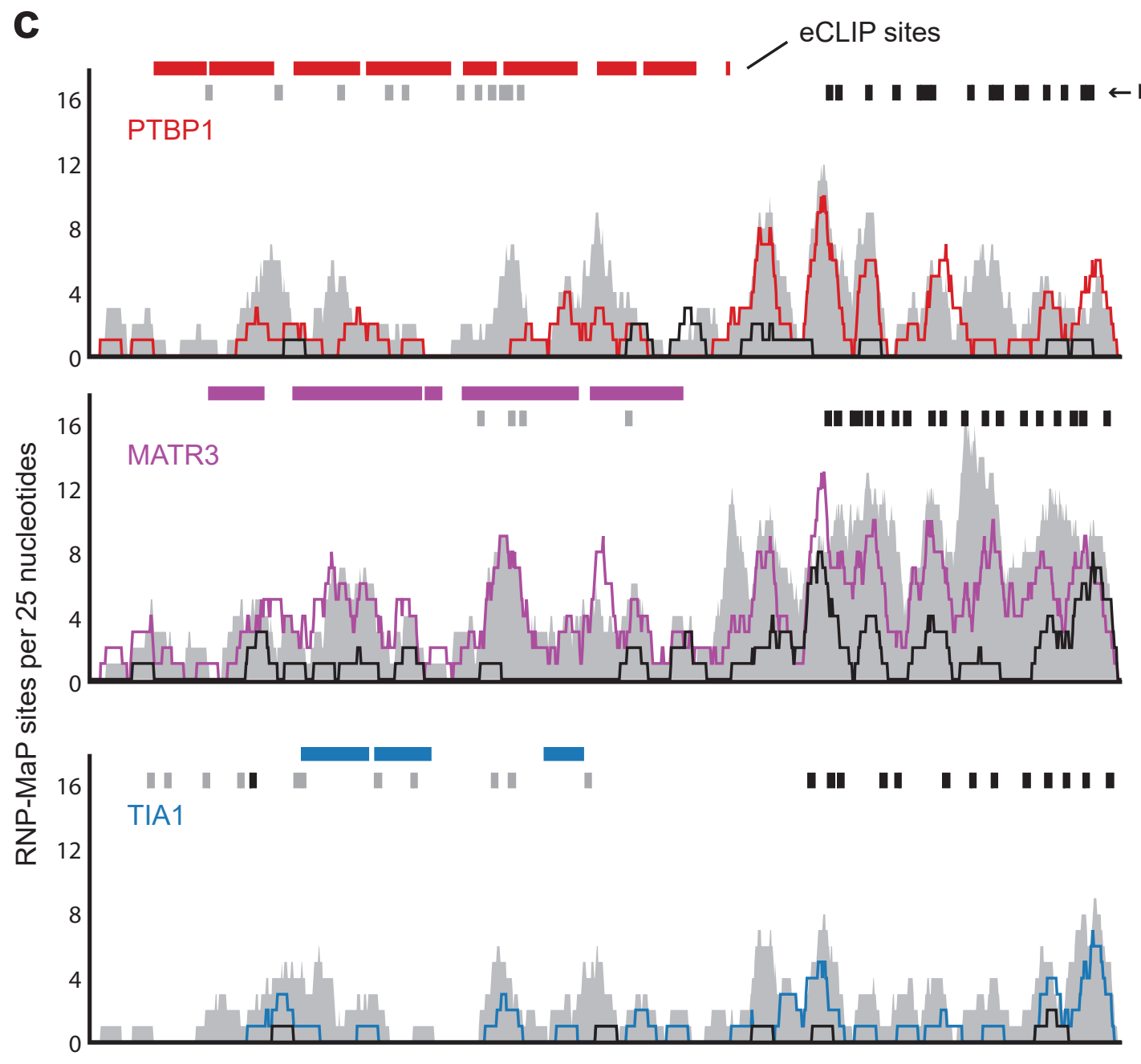

$1000 \mathrm{nM}$

$\square 500 \mathrm{nM}$

$\square 100 \mathrm{nM}$

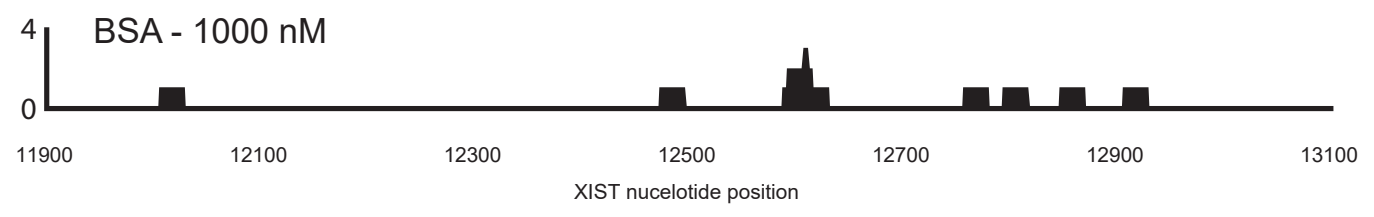

$1000 \mathrm{nM}$

$\square 500 \mathrm{nM}$

$\square 100 \mathrm{nM}$ 
bioRxiv preprint doi: https://doi.org/10.1101/2020.02.07.939108; this version posted February 9, 2020. The copyright holder for this preprint (which was not certified by peer review) is the author/funder. All rights reserved. No reuse allowed without permission.

Figure S10
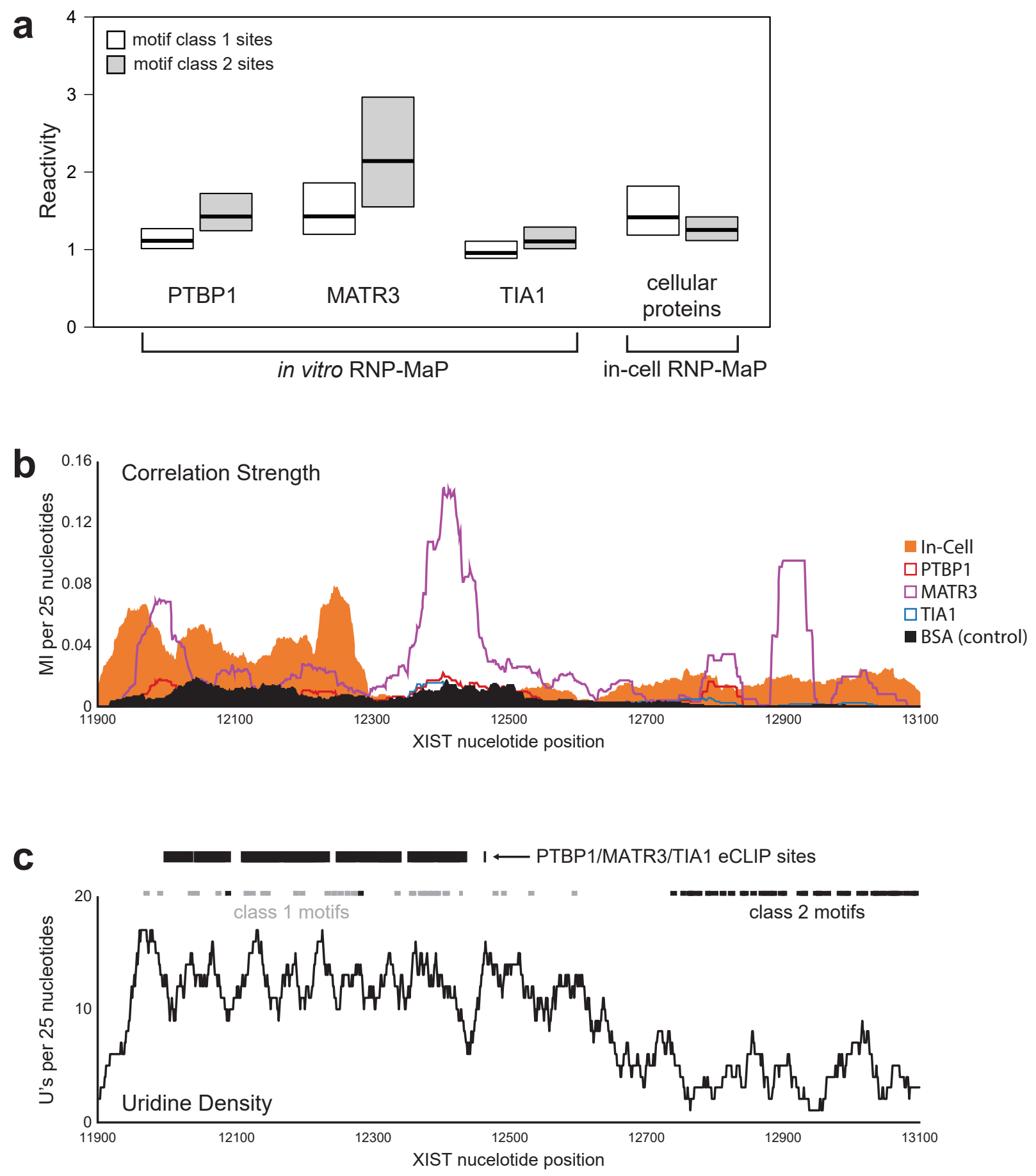